Check for updates

Cite this: RSC Adv., 2021, 11, 39027

\title{
Recent progress in Pickering emulsions stabilised by bioderived particles
}

\begin{abstract}
Kazi M. Zakir Hossain, (D) ${ }^{\text {ab }}$ Laura Deeming $^{\text {ab }}$ and Karen J. Edler (iD *ab
In recent years, the demand for non-surfactant based Pickering emulsions in many industrial applications has grown significantly because of the option to select biodegradable and sustainable materials with low toxicity as emulsion stabilisers. Usually, emulsions are a dispersion system, where synthetic surfactants or macromolecules stabilise two immiscible phases (typically water and oil phases) to prevent coalescence. However, synthetic surfactants are not always a suitable choice in some applications, especially in pharmaceuticals, food and cosmetics, due to toxicity and lack of compatibility and biodegradability. Therefore, this review reports recent literature (2018-2021) on the use of comparatively safer biodegradable polysaccharide particles, proteins, lipids and combinations of these species in various Pickering emulsion formulations. Also, an overview of the various tuneable factors associated with the functionalisation or surface modification of these solid particles, that govern the stability of the Pickering emulsions is provided.
\end{abstract}

Received 3rd November 2021

Accepted 25th November 2021

DOI: $10.1039 / \mathrm{d} 1 \mathrm{ra0} 8086 \mathrm{e}$

rsc.li/rsc-advances

systems. Typically, the phase with the better wetting capacity

\section{Introduction}

Pickering emulsions are becoming more widely used in many fields, including food, cosmetics, paints, coating, pharmaceutics, and drug delivery, ${ }^{1-6}$ although they were first reported a century ago by Ramsden in 1903 (ref. 7) and Pickering in $1907 .{ }^{8}$ In a Pickering emulsion, solid particles are allowed to accumulate at the interface between two immiscible phases to reduce the possibility of coalescence by forming a physical barrier (see Fig. 1).

A significant variety of inorganic (such as silica, clay) and organic (polysaccharides and proteins) particles have been effectively utilised as Pickering emulsifiers providing long-term emulsion stability. ${ }^{2-4,9-11}$ The key advantages of using solid particles as emulsifiers are associated with their tunable properties (such as wettability, surface charge, porosity, responsiveness etc.), and the option to select the particles from sustainable sources with biodegradability and low toxicity. ${ }^{9}$

It is very important to understand the mechanism of Pickering emulsion formation when selecting a solid emulsifier. In Pickering emulsions, the solid particles are irreversibly adsorbed at the oil-water interface to form a steric barrier resulting in a more stable emulsion formulation. The mechanism of the attachment of the solid particles at the oil-water interface mainly depends on their wettability, which determines the type of emulsion, either water-in-oil $(\mathrm{W} / \mathrm{O})$ or oil-in-water $(\mathrm{O} / \mathrm{W})$

${ }^{a}$ Department of Chemistry, University of Bath, Claverton Down, Bath, BA2 7AY, UK. E-mail:K.Edler@bath.ac.uk

${ }^{b}$ Centre for Sustainable Chemical Technologies, University of Bath, Claverton Down, Bath, BA2 7AY, UK on the solid particles becomes the continuous phase, while the other becomes the dispersed phase. More specifically, in an $\mathrm{O} /$ $\mathrm{W}$-type emulsion, the contact angle at the three-phase boundary (i.e., between the disperse phase, solid particles and continuous phase) is less than $90^{\circ}$ (i.e., hydrophilic) (see Fig. 2). ${ }^{4} \mathrm{~A}$ W/O-type emulsion forms if the three-phase contact angle is higher than $90^{\circ}$ (usually hydrophobic). However, a more stable Pickering emulsion is formed when the contact angle is close to $90^{\circ}$, where the solid particles balance their dispersion in both phases. Therefore, there is an option for the researchers to alter the surface properties (for example, wettability) of these solid particles to make them more amphiphilic.

Water-in-water $(\mathrm{W} / \mathrm{W})$ emulsions can also be formed by dispersing one aqueous phase into another aqueous phase, where the aqueous phases contain two types of hydrophilic macromolecules that are immiscible with each other. The $\mathrm{W} / \mathrm{W}$

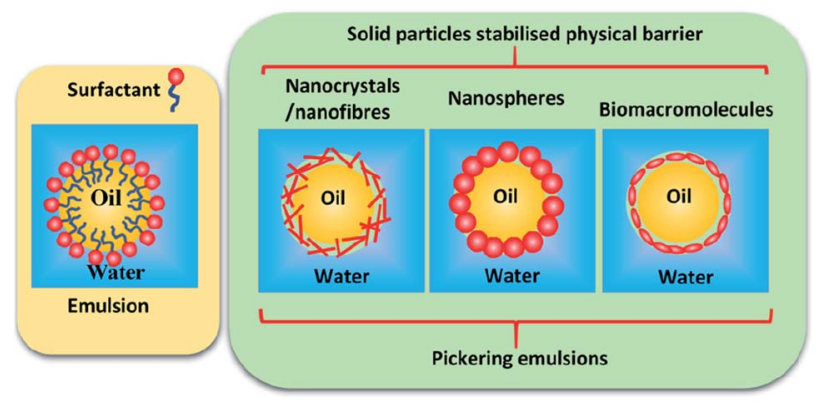

Fig. 1 Schematic representation of surfactant stabilised emulsion and solid nanoparticle stabilised Pickering emulsions. 

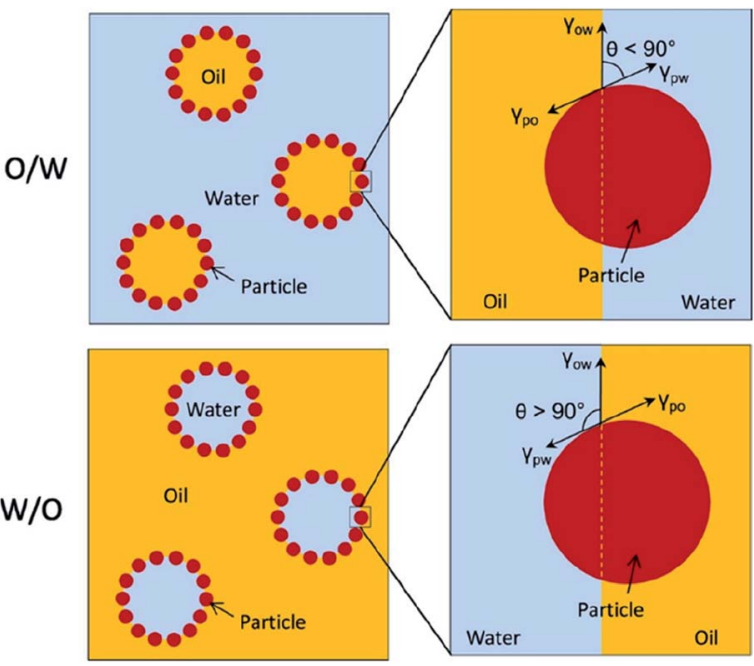

Fig. 2 Schematic representation of O/W and W/O-type Pickering emulsions governed by the wettability (contact angle, $\theta$ ) of the solid particles. ${ }^{4}$ Reprinted from ref. 4, Copyright 2019, with permission from Elsevier.

emulsions offer an oil-free system suggesting a more sustainable and greener approach than the traditional $\mathrm{O} / \mathrm{W}$ or $\mathrm{W} / \mathrm{O}$ emulsions. Moreover, in some applications such as biocatalysis, the activity of the biomacromolecules (e.g., proteins, enzymes) is enhanced in an all-water system because their activity is significantly reduced at the oil-water interface. ${ }^{12,13}$ However, stabilisation at the $\mathrm{W} / \mathrm{W}$ interface remains a challenge due to significantly lower interfacial tension. ${ }^{14}$ Various bioderived materials, such as polysaccharides, ${ }^{15}$ and protein ${ }^{13}$ macromolecules, can be effectively utilised as Pickering particles to stabilise these $\mathrm{W} / \mathrm{W}$ emulsions.

Although numerous reviews have already been published on the role of inorganic-particle-stabilised Pickering emulsions, ${ }^{16-18}$ their relatively poor biodegradability and biocompatibility significantly limit their practical applications in many fields. With increasing demand for the use of safer and sustainable materials in many applications, recently the use of natural and biodegradable organic solid particles in Pickering emulsion formulations has increased significantly. For example, various polysaccharides and natural proteins have been widely investigated recently under various conditions, such as concentration, temperature, $\mathrm{pH}$ and ionic strength. Therefore, this review highlights more recent work (2018 to 2021) using bio-derived materials as stabilisers, focusing on sustainable particles, particularly polysaccharide and proteinbased particles used in Pickering emulsions for various applications.

\section{Polysaccharides in Pickering emulsions}

Cellulose, starch, chitosan and chitin are the most common polysaccharide materials. They offer many advantageous features, including their biodegradability, biocompatibility, and low-toxicity and have been utilised in various Pickering emulsion formulations. These particles are already wellestablished in their applications in food, cosmetics, agrochemicals, pharmaceuticals, regenerated medicines and drug delivery sectors.

\subsection{Cellulose}

Cellulose is generally insoluble in water, but can undergo various chemical and/or mechanical treatments to reduce its size to nanoscale dimension either in the form of cellulose nanocrystals (CNCs) or nanofibrils (CNFs) (Fig. 3a and b). Such treatments generally also impart a surface charge to the cellulose particles, allowing them to be water dispersible. CNCs, mainly rod/needle-shaped particles with a high crystallinity ( $\sim 90 \%$ crystalline), are usually isolated from various sources (wood pulp, cotton, jute, hemp, ramie, flax, etc.) by selectively removing the amorphous regions via a controlled acid hydrolysis process. The sizes of CNCs vary between $5-10 \mathrm{~nm}$ in diameter and 100-300 nm long, depending on the cellulose sources and hydrolysis process parameters such as type and concentration of acid, hydrolysis time, and temperature. ${ }^{19-21}$
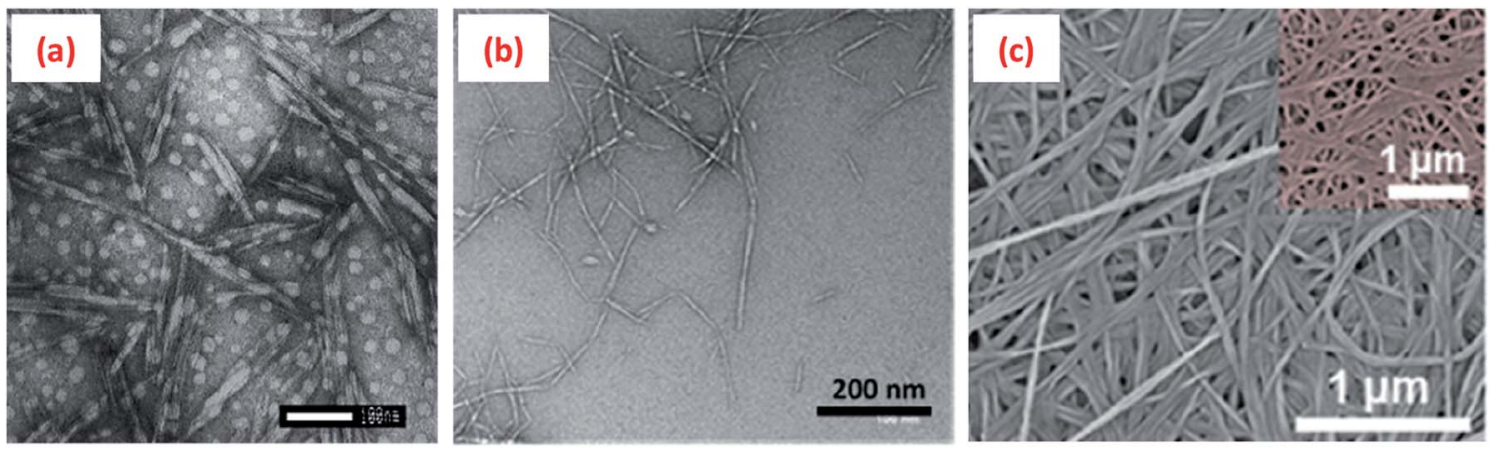

Fig. 3 Transmission electron microscopy (TEM) images of (a) cellulose nanocrystals (CNCs isolated from cotton via a sulphuric acid hydrolysis process), ${ }^{29}$ (b) cellulose nanofibrils (CNFs obtained from wood pulp utilising a high-pressure homogenisation process) ${ }^{30}$ and (c) scanning electron microscope (SEM) image of bacterial cellulose. ${ }^{31}$ Reprinted from (a) ref. 29, Copyright 2020, under the terms of the CC BY License, published by Wiley-VCH GmbH, (b) ref. 30, Copyright 2020, with permission from Elsevier and (c) ref. 31, Copyright 2020, with permission from American Chemical Society. 
CNCs with comparatively shorter length have better emulsification efficiency as the smaller sized CNCs are favourable for high coverage of oil droplets. ${ }^{22}$ The high coverage is probably obtained via side by side stacking of these particles, as well as longitudinal alignment of the self-assembled CNC particles at a relatively higher concentration. ${ }^{23}$ Usually, a form of shear is applied via a homogeniser ${ }^{24}$ or ultrasonicator ${ }^{25}$ or microfluidiser ${ }^{26}$ to disperse one phase in another and adsorb rod or fibrillar-shaped cellulose particles at the oil-water interface to form a Pickering emulsion. For example, CNCs have been used to produce low viscosity (liquid-like) O/W Pickering emulsions with precise control over the droplet sizes (around 1 to $3 \mu \mathrm{m}$ ) and high uniformity via a high energy microfluidiser. ${ }^{26}$ The emulsion stability can be controlled by the surface charge density of the CNCs since the repulsive forces between particles prevent droplet coalescence. However, an excessive surface charge density $\left(>0.03 \mathrm{e} \mathrm{nm}^{-2}\right)$ on CNCs can weaken their adsorption at the oil-water interfaces..$^{27,28}$ On the other hand, CNCs with a surface charge density of below $0.03 \mathrm{e} \mathrm{nm}^{-2}$ are found to form stable Pickering emulsions even under an applied external force field (such as centrifugation at $4000 \mathrm{~g}$ for $10 \mathrm{~min}) .^{27,28}$

CNC-stabilised Pickering emulsions have also shown excellent stability against flocculation during changes in various environmental conditions such as temperature, ionic strength, and $\mathrm{pH}$. However, in strongly acidic conditions ( $\mathrm{pH}$ below 2) and higher ionic strength (for example, $100 \mathrm{mM} \mathrm{Na}^{+}$), CNCstabilised Pickering emulsions show a gel-like behaviour. A considerable amount of protonation (at lower $\mathrm{pH}$ condition) and the presence of counter ions (dissociated from the salt) reduces the electrostatic repulsion forces between droplets,
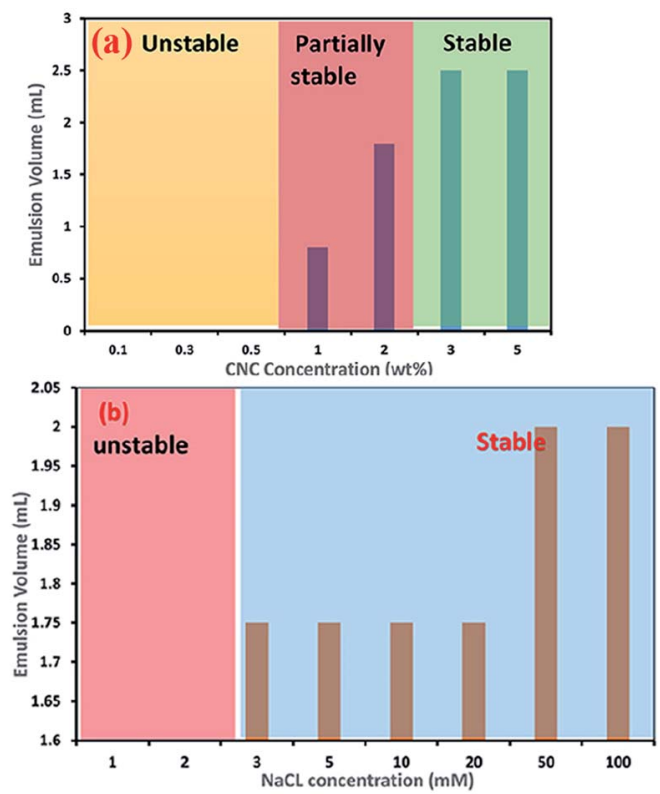

Fig. 4 Effect of (a) $\mathrm{CNC}$ concentration and (b) addition of $\mathrm{NaCl}$ to a $0.1 \mathrm{wt} \% \mathrm{CNC}$ suspension on the stability of O/W Pickering emulsions. ${ }^{32}$ Reprinted from ref. 32, Copyright 2018, under the terms of the CC BY License, published in the Frontiers in Chemistry. allowing formation of a partially flocculated gel network. This phenomenon can also be explained by the change in charge density of the cellulose nanoparticles. Higher concentrations of CNCs in aqueous dispersions with a high surface charge density usually form a stable Pickering emulsion (as can be seen in Fig. 4a, which was assessed via measuring the emulsion volume after centrifugation at $4000 \mathrm{~g}$ for $10 \mathrm{~min}) .{ }^{32}$ At higher concentrations (usually $>1 \mathrm{wt} \%$ ), a significant amount of CNC aggregates adsorb at the oil-water interface, which minimise the interfacial free energy via reduction of the interfacial area between the oil-water interfaces to stabilise the emulsion. Adding even a small amount of salt to a Pickering emulsion stabilised by a higher concentration of CNCs can lead to destabilisation of droplets due to aggregation of the surrounding gel networks caused by screening of the electrostatic repulsion forces between the CNCs. ${ }^{32}$ However, Pickering emulsions prepared using a lower concentration of CNCs can be electrostatically stabilised using mono- and divalent salts. For example, stable Pickering emulsions of canola oil in water could be formed at $0.1 \mathrm{wt} \% \mathrm{CNC}$ with addition of around $3 \mathrm{mM}$ of $\mathrm{Na}^{+}$ (see Fig. 4b) or $1 \mathrm{mM}$ of $\mathrm{Ca}^{2+}$ ions, suggesting the amount of $\mathrm{CNC}$ required to stabilise oil droplets in this Pickering emulsion was reduced by $30 \%$ when salt was added. ${ }^{32}$

Regardless of the nanocrystal size, shape and surface charge, the free hydroxyl groups present on the cellulose surface also allow different chemical reactions (such as oxidation or cationisation) to be used to tweak their hydrophilic/hydrophobic balance profile thus imparting favourable wetting properties, vital for stable Pickering emulsion formation. Unmodified cellulose is very hard to disperse in the water phase due to the lack of required surface charge and thus quite challenging to use to form a stable Pickering emulsion. CNCs are covered in anionic sulphate groups resulting from the acid hydrolysis process, rending them hydrophilic and water dispersible. However, the crystalline edge corresponding to the $200(\beta) /$ $220(\alpha)$ of the cellulose chain forms a hydrophobic face on crystalline CNC nanoparticles, which facilitates their adsorption at the oil-water interface. ${ }^{28,33}$ Also, CNCs with different crystalline allomorphs exhibit different hydrophilicity. The water contact angles for CNCs-I and CNCs-II are $44.1^{\circ}$ and $26.9^{\circ}$, respectively..$^{34}$ Due to their higher hydrophobicity, CNC-I stabilised Pickering emulsions are more stable against centrifugal forces ( $4000 \mathrm{~g}$ for $2 \mathrm{~min}$ ) than the CNC-II stabilised emulsions. ${ }^{34}$

Various hydrophobic modifications such as oxidation, esterification or graft polymerisation can also be employed to improve the hydrophobicity of CNCs, thus promoting better adsorption at the oil-water interface for stable Pickering emulsion formation. ${ }^{35-38}$ For example, the water contact angle of octenyl succinic anhydride (OSA) modified CNCs has been reported to be increased compared to unmodified CNCs, to $85.0^{\circ}$, and these particles were effectively utilised to stabilise $\mathrm{O} / \mathrm{W}$ Pickering emulsions. ${ }^{35}$ Such modifications do not significantly increase the toxicity of the polysaccharides, ${ }^{39,40}$ since they are used in food additives. Amphiphilic CNCs can also be produced by grafting hydrophobic molecules via reductive amination for more effective stabilisation of Pickering emulsions. ${ }^{\mathbf{3 8 , 4 1}}$ 
Apart from covalently bound chemical modifications, the stability of CNC-based Pickering emulsions can also be improved by incorporating additional polymers or particles via physical adsorption. For example, the addition of non-adsorbed CNFs to CNC-based Pickering emulsions is suggested to adjust the interfacial behaviour via a depletion flocculation mechanism (Fig. 5) and thus improve overall emulsion stabilisation. ${ }^{42}$ Depletion flocculation in an emulsion system is associated with an increase of attractive interactions between the droplets, and these attractive interactions can be induced via the exclusion of some CNFs from the confined regions surrounding the oil droplets (Fig. $5 \mathrm{c}$ ). At the CNF critical flocculation concentration, a concentration gradient is created between the bulk suspension (with a high CNF concentration) and the depletion zone (low CNF concentration around the oil droplets), which influences the droplet attraction (mainly originating from osmotic pressure changes between droplets) resulting in droplet flocculation. However, increasing the CNF concentration still further resulted in the formation of a CNF gel, resulting in a lack of droplet creaming, although both flocculated and stable oil droplets were present.

In comparison with CNCs, CNFs are longer fibrillar structures with a substantial aspect ratio (length around a few hundreds of nanometres and a cross-section below ten nanometres $)^{43}$ which are processed utilising various mechanical disintegration approaches, mainly via high-pressure homogenisation, ultrasonication and grinding. ${ }^{44-46}$ Usually, CNF production via a mechanical process is associated with high energy consumption. ${ }^{\mathbf{4 4 , 4 7}}$ Also, most of the fibrils obtained via mechanical treatment are in the form of bundles of fibrils rather than the individual fibre. Cellulose nanoparticles having a lower surface charge (for example, $\zeta$-potential values between $\pm 30 \mathrm{mV}$ ) possess weak mutual electrostatic repulsion forces, which leads to the formation of aggregated networks. ${ }^{23}$ Therefore, a chemical pre-treatment on the source cellulose is generally required before the mechanical defibrillation process to cut the processing time (thus, reduce the energy consumption) and also to impart the necessary charge on the cellulose surface to aid the individualisation of the nanofibrils at a relatively dilute concentration due to the repulsive forces. For example, 2,2,6,6-tetramethylpiperidine-1-oxyl radical (TEMPO)mediated oxidation of hardwood celluloses is commonly used, prior to processing via a high-pressure homogeniser, to produce oxidised cellulose nanofibrils (OCNF). ${ }^{48,49}$ The TEMPOmediated oxidation process allows the selective conversion of C6-primary hydroxyl groups on the cellulose surface to C6carboxyl groups, thus increasing negative surface charge. ${ }^{49}$ The $\zeta$-potential value of the TEMPO-mediation OCNF (with the degree of substitution $\sim 25 \%$ ) is around $-60 \mathrm{mV}$ (ref. 50 and 51) and their typical dimensions are around 3-5 $\mathrm{nm}$ in diameter and several microns in length. ${ }^{52,53}$

Anionic CNFs are suggested to form an inter-connected fibrillar network at the oil-water interfaces during Pickering emulsion formation. ${ }^{51,54}$ In addition, relatively long fibrous CNFs may adsorb slowly to the droplet surfaces during homogenisation and form relatively thick interfacial layers. Shell thicknesses above $100 \mathrm{~nm}$ with a hydration layer have been reported. ${ }^{51}$

Greater adsorption of CNF at the oil-water interface with improved emulsion droplet stability can be governed by (a)

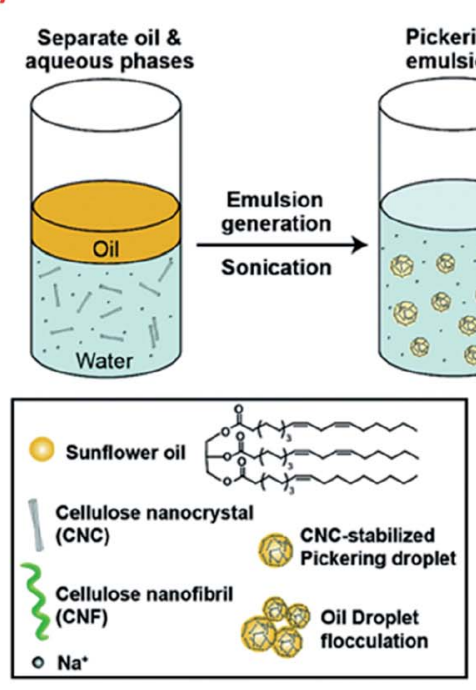

(b)

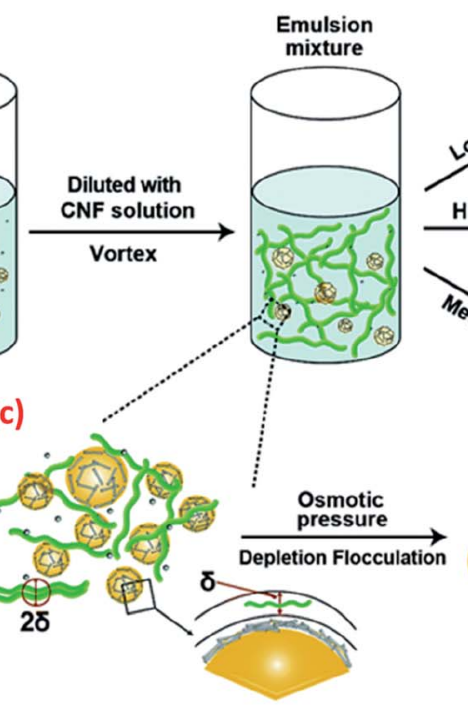

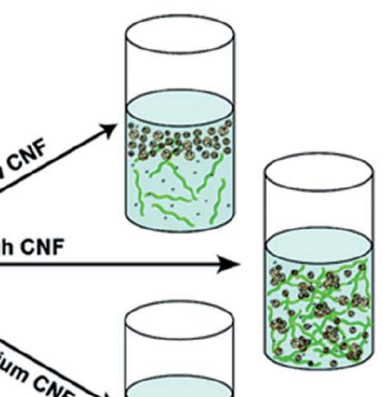

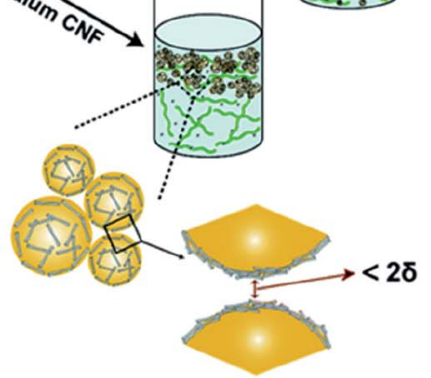

Fig. 5 Schematic illustration of (a) the CNC-stabilised Pickering emulsion droplets that are further stabilised by the addition of CNF, (b) with various CNF concentrations, different stabilisation regimes are shown, and (c) Depletion flocculation of oil droplets in the CNC-stabilised Pickering emulsions is shown with non-adsorbed CNF reaching the critical flocculation concentration. The symbol $\delta$ in this scheme is used to indicate the size of single CNF or CNF flocs in the aqueous phase. ${ }^{42}$ Reprinted from ref. 42, Copyright 2018, with permission from the Royal Society of Chemistry. 
increasing the oil-water interfacial tension as investigated using various types of oils. ${ }^{55}$ The amount of CNFs adsorbed on the droplets also increases the interfacial area, calculated using the diameter of the oil droplets. ${ }^{55}$ However, the dispersion stability of CNFs-stabilised droplets depends on the critical concentration of CNFs (in the aqueous phase) rather than those adsorbed on the droplets. Above this concentration, the CNFs form interconnected networks in the water phase resulting in effective stabilisation against creaming, as demonstrated by Bai et al. $^{42}$ in Fig. 5.

Since the anionic CNFs possess a highly negative charge on their surface ( $\zeta$-potential $\sim-60 \mathrm{mV}),{ }^{50}$ emulsion droplets stabilised using these particles also experience electrostatic repulsion with the surrounding droplets, which can be screened by the addition of salt. ${ }^{51}$ For example, the addition of $\mathrm{NaCl}$ salt $(0.5 \mathrm{M})$ to an anionic CNF-stabilised Pickering emulsion lowered the surface charge of the emulsion droplets, as the $\zeta$ potential values decreased from -46 to $-5 \mathrm{mV}$ which resulted in droplet aggregation as confirmed via confocal microscopic images. ${ }^{51}$ On the other hand, cationic CNFs (functionalised using glycidyl trimethylammonium chloride with degree of substitution $\sim 23 \%$ and $\zeta$-potential $\sim+37 \mathrm{mV}$ ) used to stabilise a Pickering emulsion had very little response to salt, as the $\zeta$ potential of the droplets decreased only from +24 to $+13 \mathrm{mV}$ for emulsions after addition of $\mathrm{NaCl}(0.5 \mathrm{M}) .^{51}$

Bacterial cellulose nanofibres (BCN), with a diameter ranging from 25-100 $\mathrm{nm}$ and length from $100 \mathrm{~nm}$ to several micrometres (Fig. 3c), are biosynthesised by bacteria in their aqueous culture medium. ${ }^{56}$ Sulphuric acid hydrolysed BCNs possess a higher surface charge $(\zeta \text {-potential }-34.8 \mathrm{mV})^{57}$ than the native fibres and can be well-dispersed in aqueous phase to form a flocculated fibrillar network, which is favourable to stabilise Pickering emulsions. ${ }^{57,58}$ Like CNFs, BCNs are also suggested to adsorbed at the oil-water interface at a higher concentration to form a stable Pickering emulsion. ${ }^{57}$

Apart from CNCs and CNFs, micron-sized fibres, such as cellulose microfibres (CMFs), can also be used as emulsion stabilisers by providing a denser packing of fibrils (usually by increasing the concentration of the micron-sized fibrils) which acts as a solid mechanical steric barrier around the droplets to prevent coalescence and creaming (Fig. 6) ${ }^{59}$ The stability of this type of emulsion was however considered more likely to be due to the formation of a gel-like microfibril network around the droplets rather than the adsorption of the cellulose particles at the oil-water interface.

\subsection{Starch}

Starch, the second most abundant polysaccharide after cellulose, is also extensively used to stabilise Pickering emulsions for multiple purposes, mainly in the food industries. Starch consists of amylose (linear glucose units) and amylopectin (branched glucose units) which can form both soluble polymers and insoluble particles in water. The dispersibility of starch in water depends on the ratio of amylose and amylopectin present in the starch, which depends on its source. Common sources include potato, corn, rice, wheat, maise, and cassava starch. ${ }^{60}$ Therefore, the emulsification ability of starch depends on the starch source and type. Starch particles can adsorb on oil droplets and also form an inter-droplet network leading to gellike behaviour in the Pickering emulsions. However, starch in its native granular form is not hydrophobic and hence not suitable to adsorb at the oil-water interface during the emulsification process. The hydrophobicity of starch can be increased by chemical or physical modification. Starch molecules can be chemically modified via esterification with octenyl succinic anhydride (OSA) to improve their hydrophobicity and thus increase the affinity of the starch particles to oil. ${ }^{61-64}$ Although the particle size distribution of the native starch is not significantly influenced by the OSA-esterification; ${ }^{65}$ the hydrophobic modification in turn, resulted in smaller droplet sizes in the emulsion, slower creaming and better stabilisation of the

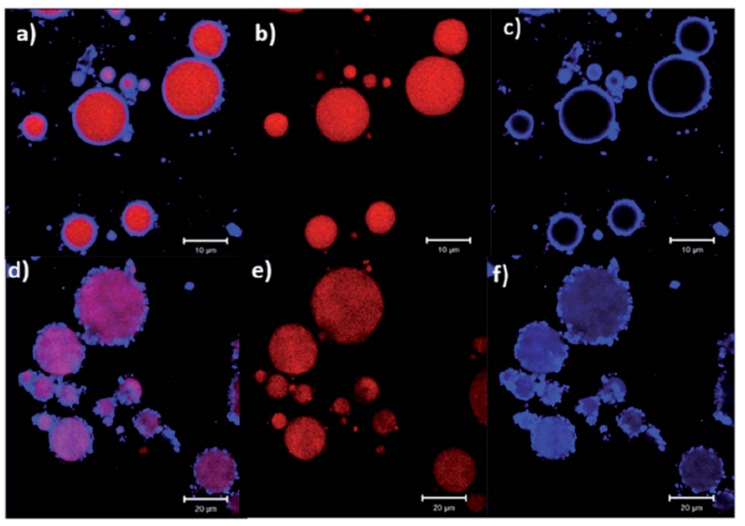

Fig. 7 Confocal micrographs of Pickering emulsions prepared with $(a-c) 20 \%$ wt of native starch, and $(d-f) 20 \%$ wt of modified starch (esterified with lauroyl chloride). ${ }^{66}$ Reprinted from ref. 66, Copyright 2018, with permission from Elsevier

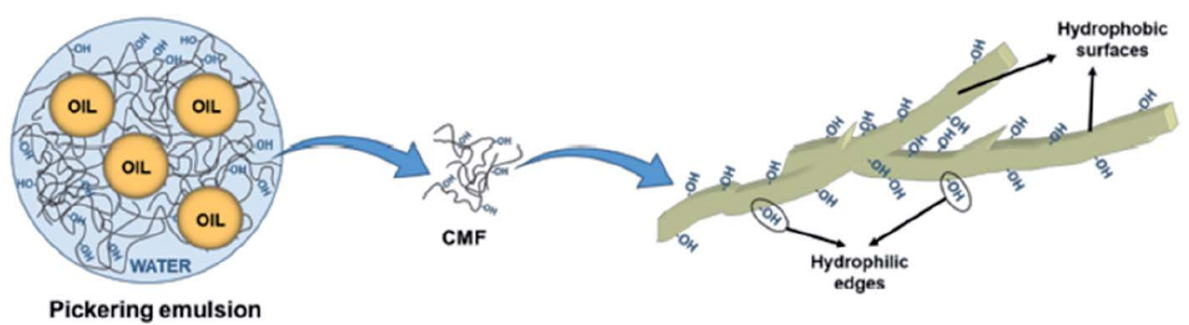

Fig. 6 Role of cellulose microfibrils in O/W type emulsion formulation. ${ }^{59}$ Reprinted from ref. 59, Copyright 2019, under the terms of the CC BY License, published by MDPI. 
Pickering emulsion than emulsions prepared with unmodified starch. ${ }^{62,66}$ In addition, OSA-modifications are not considered as toxic since they are used in food additives. ${ }^{39,40}$

Confocal microscopy images of starch-stabilised Pickering emulsions are shown in Fig. 7 (blue regions correspond to starch and red areas are those of the oil phase), where the droplets of emulsion prepared with unmodified native amaranth starch show a lower coverage of the oil phase compared to those prepared with modified starch (esterified with lauroyl chloride). ${ }^{66}$ Such hydrophobic modification of starch can also lead to the formation of aggregated particles in the aqueous phase and which adsorb at the oil-water interface as aggregates rather than individual particles providing local larger thicknesses of starch on the oil droplets at the adsorption sites (Fig. 7). ${ }^{66}$

Decreasing starch particle size also tends to decrease Pickering emulsions' droplet size while increasing storage stability ${ }^{67}$ The decreased particle size provides a better cohesive barrier at the oil-water interface due to more efficient packing. Different processes, such as acid hydrolysis, ${ }^{68}$ non-solvent precipitation, ${ }^{69}$ ultrasonication, and media-milling, ${ }^{70}$ are commonly used to reduce the starch particle size. However, in terms of sustainability it is preferred to avoid using corrosive acids, toxic chemicals and ultrasonication processes (which utilise high energy and are limited to small volume production). Hence, less toxic chemical treatments along with milling or high-pressure homogenisation processes can be employed for large scale production of reduced sized starch particles in a more sustainable way.

\subsection{Chitosan}

Chitosan is a linear polysaccharide obtained by the deacetylation of chitin, naturally occurring in the exoskeletons of crustaceans, insect cuticles and cell walls of some fungi. Chitosan possesses antibacterial, antifungal, mucoadhesive and gelling properties, making it a promising material for many industrial applications, especially candidates in tissue engineering and drug delivery, although concerns about allergic reactions to marine proteins can limit its use in such products. Chitosan is usually soluble in a dilute acidic medium due to the protonation of the free amino groups on their surface, which leads a weak surface activity resulting in the poor emulsifying capacity. Usually, by increasing the $\mathrm{pH}\left(\mathrm{pH}>\mathrm{p} K_{\mathrm{a}}\right)$ close to neutral, deprotonation of $\mathrm{NH}_{3}{ }^{+}$group to $\mathrm{NH}_{2}$ results in a decrease in the net charge of the chitosan molecules, which increases their intermolecular attraction and intensifies the hydrophobicity to form self-aggregated chitosan particles (with mean diameter $\sim 287 \mathrm{~nm}$ and $\zeta$-potential $\sim+24 \mathrm{mV}$ ). ${ }^{71}$ Chitosan has been investigated to stabilise Pickering emulsions by increasing the continuous phase viscosity or by forming a layer (via self-aggregation $)^{71}$ at the surface of the dispersed oil droplets. In addition, the hydrophobicity of the chitosan particles can also be tailored with the addition of various oppositely charged surface-active agents such as polyanions, ${ }^{72}$ proteins ${ }^{73}$ or other polysaccharides ${ }^{74-76}$ forming complex coacervates where

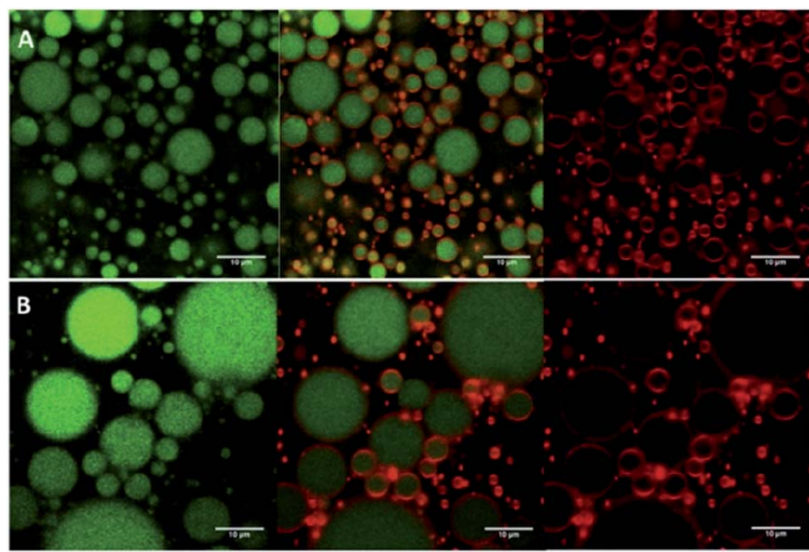

Fig. 8 Confocal laser scanning microscopy images of Pickering emulsion formulations prepared with a fixed concentration of chitosan/gum arabic $(1: 1)$ nanoparticle dispersion $(1.5 \% \mathrm{w} / \mathrm{v})$ and an oil volume fraction of (A) $\varphi=0.5$; and (B) $\varphi=0.7$. The emulsion oil phase appears in green (on the left), whereas the adsorbed nanoparticles appear in red (on the right). The images in the middle are an overlay of these two images (right and left). ${ }^{76}$ Reprinted from ref. 76, Copyright 2019, with permission from Elsevier.

the hydrophilicity can be tuned to improve emulsifying capacity.

Pickering emulsions prepared from chitosan/gum arabic $(1: 1)$ dispersions $(1.5 \% \mathrm{w} / \mathrm{v}$, with average diameter $\sim 108 \mathrm{~nm}$ and $\zeta$-potential $\sim+56 \mathrm{mV})$, and high oil volume fractions $(\varphi=$ $0.5,0.7$ ), have shown good storage stability via the effective adsorption of the complex particles (formed via electrostatic attraction between the positively charged chitosan and negatively charged gum arabic) at the oil-water interface, forming a barrier against droplet coalescence (see Fig. 8) ${ }^{76}$ Moreover, by increasing the oil volume fraction and the concentrations of the particles, gravitational phase separation during long-term storage was inhibited.

\section{Proteins in Pickering emulsions}

Proteins are one of the most commonly used classes of stabilisers for Pickering Emulsions, so the literature around the use of protein particles for Pickering emulsion is extensive and includes applications such as drug delivery, ${ }^{77}$ biocatalytic activity $^{12,13,78}$ and encapsulation of nutritional agents like Vitamin $\mathrm{D}_{3} \cdot{ }^{79}$ Current research is focused on a wide variety of protein-based Pickering stabilisers with differing tuneable characteristics. The stabilisation of the emulsion works through steric repulsion of the particles as well as strong electrostatic repulsions between the charged surface-active particles. The inherent bioderived nature of proteins makes them an attractive edible choice for the food industry which has been discussed in depth in recent reviews. ${ }^{80-82}$ With a rise in vegetarianism, veganism and for religious reasons, there has been growing demand from consumers for emulsion-based protein products that are not sourced from animals. This has driven a greater focus on investigating the emulsification properties of various food-grade plant proteins such as pea 
protein, ${ }^{83}$ Persea americana Mill ${ }^{84}$ (a by-product of avocado oil processing) and peanut protein ${ }^{\mathbf{8 5 , 8 6}}$ as replacements for animalbased proteins. These plant proteins can be more sustainable, have excellent emulsion capabilities and are usually less expensive than more commonly used dairy proteins, however are usually less soluble in aqueous solutions and are less digestible. $^{83}$

Protein-based emulsion stabilising particles can be broken down into two key classes - 'nanoparticles' and 'gel network particles', although there are other shapes including nanofibrils and nanocages, which were discussed in depth in a recent review, ${ }^{\mathbf{8 1}}$ so these will not be included here. Protein nanoparticles have various simple preparation methods including emulsification, complex coacervation and electrospray. Due to their ease of adsorption at the oil-water interface and cost effectiveness, nanoparticles have dominated most previous protein-based Pickering emulsion studies. Protein nanogel particles however are now of increasing interest to form responsive Pickering emulsions, so both of these classes of protein-based Pickering stabilisers are discussed below.

Curcumin, a lipophilic polyphenol derived from the turmeric plant, has been suggested to have many health benefits such as being an anticarcinogenic, anti-inflammatory and antioxidant. However, due to its high hydrophobicity, chemical instability, and poor bioavailability, it has not been fully utilised in modern medicine and research has escalated towards finding the right delivery vector to encapsulate the nutraceutical for ingestion. Curcumin encapsulation is used here as an example to demonstrate the potential of a variety of protein-based systems for Pickering emulsion stabilisation and delivery of such actives. Pickering emulsions have shown excellent potential to improve the oral bioavailability of lipophilic species with the physical barrier at the interface of the droplets able to protect the active species from physiologically harsh conditions. For example, ovotransferrin fibrils, a glycoprotein derived from eggs, have been investigated as an efficient Pickering stabiliser that can also protect encapsulated curcumin from UV degradation. ${ }^{87}$ Increasing the salt concentration present in solution to $1000 \mathrm{mM}$ and adjusting to $\mathrm{pH} 6$ gave the emulsion the best stability and UV protection as it was hypothesised that with a reduced electrostatic repulsion, the fibrils could form a denser, thicker shell around the encapsulated curcumin. While these optimal salt and $\mathrm{pH}$ conditions are obviously unrealistic for physiological uses, the bio-accessibility of curcumin increased up to $129 \%$ using a TIM-1 digestion model under more realistic physiological conditions showing the potential that ovotransferrin fibres hold for future uses as a means of encapsulating curcumin.

Pickering emulsions have also been explored to influence a higher level of organisation within a system, using the stability of the particle stabilised emulsion to embed it in a hydrogel network. Double cross-linked zein-sodium alginate emulsion gels, using a Pickering emulsion template, with a dense network microstructure and high viscoelasticity were able to encapsulate two nutraceuticals - curcumin and resveratrol. ${ }^{88}$ The double cross-linked system contained transglutaminase-linked zein nanoparticles adsorbed to oil droplets, to form a Pickering emulsion, which were then embedded in a calcium alginate cross-linked network. This gave an emulsion gel with superior nutraceutical bio-accessibility and light stability in comparison to a single cross-linked system. The adsorption of the anionic biopolymer, sodium alginate, provided additional protection against coalescence of oil droplets by increasing the electrostatic and steric repulsion between them and an increased concentration of transglutaminase led to stronger gel formation through further cross-linking. Modifying the protein surface using biopolymers such as carboxylmethyl dextran ${ }^{89}$ has been shown to also increase the bio-accessibility of curcumin in protein-stabilised Pickering emulsions by reducing the hydrophobicity of the protein surface. Other hybrid particle complexes have also been investigated in relation to curcumin encapsulation including gliadin (protein)-lecithin (phospholipid), ${ }^{90}$ whey protein isolate (protein)-lactose (polysaccharide)epigallocatechin gallate (polyphenol) ${ }^{91}$ and phosphatidylcholine (phospholipid)-kaolinite (clay). ${ }^{92}$ This wide variety of complexes demonstrates the versatility and tunability of protein based particles for Pickering emulsion stabilisation and the potential for using the Pickering stabilised emulsion droplets as building blocks in more complex delivery systems.

High Internal Phase Emulsions (HIPEs) have also received increased interest in recent years. They are defined as having an internal phase volume of at least $74 \%$ and in the past have commonly required a high concentration (5-50 wt\%) of surfactants to prevent flocculation of the droplets, which can be considered a potential environmental problem. Research has therefore turned to High Internal Phase Pickering Emulsions (HIPPEs) as an alternative. Above this defined volume, the oil droplets tend to deform from spherical to polyhedral in shape to increase the packing and the emulsion becomes highly viscous. Inorganic particles such as silica ${ }^{93}$ and titania ${ }^{94}$ have been explored to stabilise HIPPEs but the potential release of non-degradable particles has led to a shift in focus to food grade biopolymer-based particles such as peanut protein isolate, ${ }^{86}$ perilla protein isolate ${ }^{95}$ and casein nanogels ${ }^{96}$ because of their biocompatible nature. A large benefit of the high oil volume capacity of HIPPE is that the emulsion has a greater loading capacity for hydrophobic compounds during encapsulation, however, there is the risk of phase inversion within the emulsion at such high oil volumes.

HIPPEs have the potential to reduce the need for partially hydrogenated oils (PHOs) in food products by forming solid-like fats from highly concentrated liquid oils. However, common protein particles e.g. zein and whey protein isolate (WPI) tend to rearrange at the biphasic interface when used as the sole stabiliser leading to lower stability of the emulsion. This has led to a search for novel proteins to use as a sole stabiliser for HIPPEs with Zhao et al. pioneering the use of perilla protein isolate, a by-product residue from the processing of perilla oil..$^{95}$ Initial studies found the defatting methods to isolate the protein residues significantly impacted its functional properties such as foamability and solubility. Cold-pressed residues displayed the most promising properties, albeit at high $\mathrm{pH}$, such as small droplet sizes $(27.55 \mu \mathrm{m})$, high foaming ability $(90.67 \%$ at $\mathrm{pH} 11)$ and good emulsification ability $\left(3390.1 \mathrm{~m}^{2} \mathrm{~g}^{-1}\right.$ at $\left.\mathrm{pH} 11\right)$, for 
future use as Pickering stabilisers in comparison to hot pressing and solvent extraction methods. The improved performance was due to the protein particles forming at a smaller size (318 $\mathrm{nm}$ ), with high hydrophobicity, the largest electrostatic repulsion, and a higher solubility than alternative defatting methods. However, the oil fraction limit for the emulsion was capped at $\varphi$ $=0.5$ (ref. 97) so this group went on to combine the particle preparation method of $\mathrm{pH}$ cycling (which can give a heterogeneous distribution of particle sizes) with further homogenisation through high speed shearing to give perilla protein nanoparticles (PNPs) that could form HIPPEs with a gel-like network and an oil fraction up to $\varphi=0.75$ with as small PNP concentration as $1 \% .{ }^{95}$ Despite this improvement, future work must continue to increase the oil fraction dispersed by the particles to be seen as a viable option as a HIPPE which is competitive with current surfactant-based technologies. Other groups are focused on casein nanogels ${ }^{77}$ and egg proteins ${ }^{98}$ to achieve viable HIPPE systems.

Microgels and nanogel Pickering particles, of micrometre and nanometre size respectively, have also recently been brought to the forefront of research. They are soft colloidal particles that hold the ability to swell upon solvent addition and are prepared commonly through top-down methods. A crosslinked hydrogel is formed from a concentrated protein source and then homogenised and broken down into smaller gel particles under shear. Three-dimensional gel networks are formed when there is a high concentration of non-adsorbed
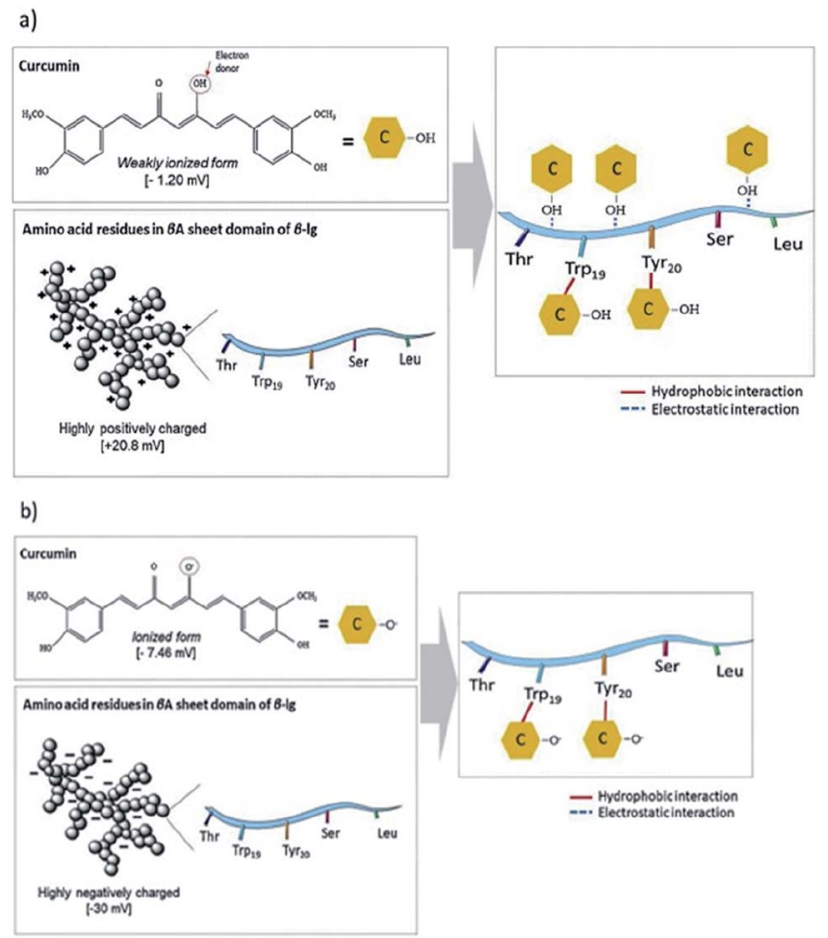

Fig. 9 Schematic representation of the non-covalent binding interactions of whey protein nanogel with curcumin at (a) $\mathrm{pH} 3.0$, and (b) $\mathrm{pH} 7$, respectively. The grey spheres represent WPN and yellow hexagons represent curcumin. ${ }^{99}$ Reprinted from ref. 99, Copyright 2019, with permission from Elsevier. particles with strong electrostatic forces from the protein functional groups keeping the network rigid and have been shown to improve the stability of emulsions as the oil droplets cannot aggregate due to the network rigidity, giving them semisolid characteristics. Nanogel particles have been used much less commonly as Pickering stabilisers in comparison to microgels, with few examples in literature in recent years. ${ }^{77,99,100}$

A protein by-product of the cheese industry, whey protein isolate (WPI), has previously been used as a stabiliser both alone ${ }^{101}$ and as a hybrid with other biopolymers. ${ }^{91,102}$ It is limited in its use due to its tendency to denature during the pasteurisation stage. Whey protein microgel (WPM) particles can be formed when WPI is heated to high temperatures ${ }^{\mathbf{1 0 3}}$ or subjected to hydrostatic pressures ${ }^{\mathbf{1 0 4}}$ at a $\mathrm{pH}$ close to the isoelectric point (pH 5.0-6.0).

Smaller whey protein nanogel (WPN) particles, with $83.05 \pm$ $1.74 \mathrm{~nm}$ particle diameters, formed by passing a heat-set hydrogel through a high pressure homogeniser twice, have been used as a Pickering stabiliser for curcumin encapsulation where the small, nanometric sized gaps between the particles $(\sim 30 \mathrm{~nm})$ at the droplet interface prevented curcumin diffusion out of the oil droplet. ${ }^{99}$ The $500 \mu \mathrm{g} \mathrm{ml}^{-1}$ of curcumin within the droplets was shown to bind through hydrogen bonding and electrostatic interactions to the nanogel particles and remained stable under physiologically relevant conditions, showing promise for use as a future delivery vector. ${ }^{99}$ Varying the $\mathrm{pH}$ of the system greatly altered the binding affinities and binding mechanisms of the curcumin to the WPN particles as shown in Fig. 10. At lower pH values, the amino acid residues in WPN are
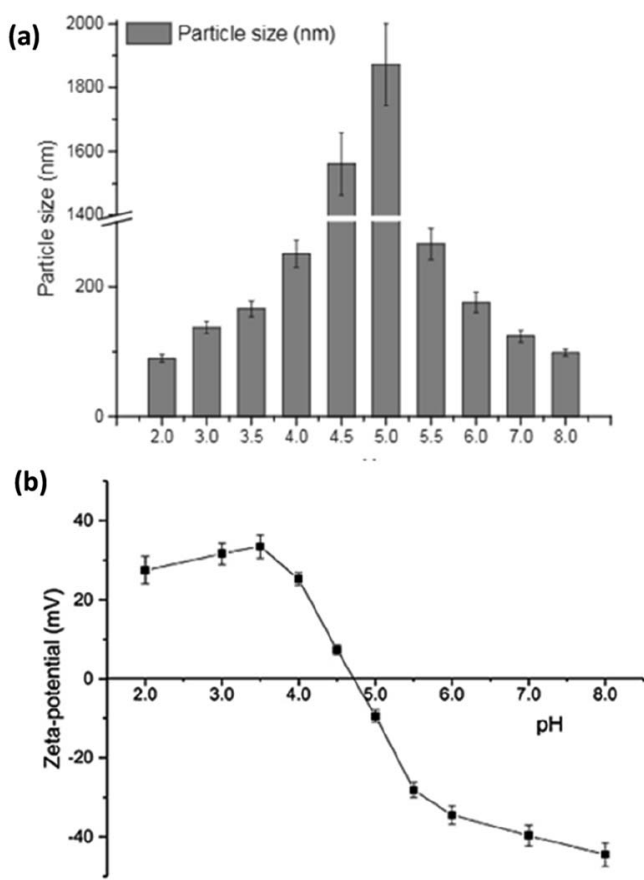

Fig. 10 The mean particle size (a) and $\zeta$-potential (b) of whey protein isolate (WPI) gel particles, produced using high hydrostatic pressures, as a function of $\mathrm{pH}^{104}$ Reprinted from ref. 104, Copyright 2020, with permission from Elsevier. 
positively charged leading to strong electrostatic attractions with the weakly negative charge of the curcumin (Fig. 9a). However, at higher $\mathrm{pH}$ values, the main form of bonding interaction is from hydrophobic interactions as both the WPN and curcumin possess negative charges (Fig. 9b). The difference in gel particle size between nano- and micro-examples formed under hydrostatic pressures has been attributed to small differences in preparation routes with a highly localised pressure, less turbulent flow and a lower protein concentration in the heat set hydrogel seeming to lead to smaller nano-sized gel particles.

HIPPEs stabilised solely by protein particles can also be improved upon by using the protein microgel particle counterpart as the Pickering stabiliser. ${ }^{103}$ In comparison to native non-gelled WPI particles and a standard surfactant (Tween 20), HIPPEs formed using WPM particles had a better thermal stability, greater shelf life and were overall more viscous. ${ }^{\mathbf{1 0 3}}$

During particle preparation using high hydrostatic pressure, the diameters of the WPM particles varied greatly depending on the $\mathrm{pH}$ of the aqueous conditions. ${ }^{\mathbf{1 0 4}}$ As the $\mathrm{pH}$ approached the isoelectric point (pI), the $\zeta$-potential of the gel particles reached a point of zero charge. This led to less electrostatic repulsion occurring (Fig. 10b) and micrometric sized particles forming (Fig. 10a) around the pI as opposed to the nanometric sized particles both above and below this $\mathrm{pH}$. The combination of lower electrostatic repulsion and larger particles produced a tighter internal structure, and more rigid packing at the interfaces, ideal stabilisers for formation of Pickering emulsion gels that had a lower release profile for the nutraceutical curcumin than liquid Pickering emulsions. This same particle size trend occurred for both peanut protein ${ }^{86}$ and pea protein ${ }^{83}$ microgel emulsions as aggregates formed at the isoelectric point. Crosslinking WPM particles with organic acids, such as citric and tannic acid, has been shown to produce smaller, less polydisperse particles that also appeared to offer a better emulsion stability compared to conventional WPM stabilised emulsions. $^{\mathbf{1 0 5}}$

Protein nanoparticles and micro or nanogels are therefore promising bioderived materials for future studies with a large range of possible protein sources, especially considering the potential for valorisation of waste generated in other food processing steps.

\section{Lipid nanoparticles}

The term lipid is used to encompass a large and diverse range of molecules that retain the key feature of organic compounds that are insoluble in water. Edible lipid particles have become increasingly studied as Pickering particles due to their biocompatibility and ease of production. This section will focus on recent trends involving solid lipid nanoparticles and oleofoams.

\subsection{Solid lipid nanoparticles}

Polymer nanoparticles have commonly been used as a drug delivery encapsulation option, however the cost of production and regulatory restrictions on safety has led to research into alternatives such as Solid Lipid Nanoparticles (SLNs) which offer a reduced toxicity and better biocompatibility. It has been proposed that SLN-stabilized Pickering emulsions could act as temperature sensitive nano-carriers, with ketoprofen used as a model hydrophobic drug solubilised in medium chain triglycerides (MCT). ${ }^{106}$ The nano emulsion was stabilised using $40 \mathrm{~nm}$ sized SLNs and at physiological temperatures $\left(37^{\circ} \mathrm{C}\right)$, there was partial melting of the SLNs which led to a slow drug release as the barrier between the oil and the aqueous phase weakened. A recent proof-of-principle study also explored the potential of co-encapsulation and co-delivery of hydrophobic and hydrophilic active ingredients within the same emulsion. ${ }^{\mathbf{1 0 7}}$ First, a model hydrophobic active ingredient, Sudan III, was encapsulated within the SLN itself then depending on the type of emulsifier used to stabilise the SLNs, dimethylphthalate (DMP) and $\mathrm{NaCl}$ were encapsulated within a $\mathrm{O} / \mathrm{W}$ and $\mathrm{W} / \mathrm{O}$ emulsion respectively. ${ }^{\mathbf{1 0 7}}$ The potential for multi modal drug delivery of both hydrophobic and hydrophilic actives is a highly desirable concept, diminishing the need for multiple doses as well as offering potential synergistic benefits.

The inherent hydrophobicity of the lipid particles leads to the need to incorporate small amounts of surfactants or other emulsifiers in the formulation stage to tune the hydrophobic nature and minimise coalescence of droplets. This makes it an option that cannot feasibly be surfactant-free but there is a reduced toxicity risk in comparison to a system stabilised exclusively by surfactants due to the lower concentrations. It has been shown that there is a strong correlation between the type and concentration of emulsifiers used during formulation of the SLNs and the interfacial properties of the particles formed. ${ }^{\mathbf{1 0 8 , 1 0 9}}$ Recent studies showed the De Brouckere $\left(D_{4,3}\right)$ mean diameters of SLNs reduced in size significantly with the increasing concentration of different PEGylated emulsifiers used in the preparation. Increase of the surface load of the emulsifiers $\left(\Gamma_{\mathrm{s}}\right)$ led to the decrease in contact angle between the SLNs and the oilwater interface, closer to the optimal $90^{\circ}$ angle, with the SLN prepared using a Brij S20 emulsifier decreasing from $\sim 155^{\circ}$ to $135^{\circ}$ as the surface load increased from 10 to $20 \mathrm{mg} \mathrm{m}^{-2} .^{108}$

A common method of preparation of SLNs involves heating the lipid phase above its melting point, then addition of the aqueous phase containing small amounts of the emulsifier at the same temperature. ${ }^{\mathbf{1 1 0}}$ The phases are then emulsified, and the nanoparticles formed, commonly by high shear homogenisation or ultrasonic treatment, which can lead to a more stable emulsion containing smaller droplets with an average diameter typically under $300 \mathrm{~nm}$ and a narrow particle size distribution.

Freeze drying (lyophilisation) is a common method in the food industry for preserving perishables through the removal of water before rehydrating at a later date. Zafeiri et al. investigated the effect of dehydration/rehydration on SLN-stabilised Pickering emulsions to determine how particle morphology and size changed with varying factors such as lipid type, surface active species type and concentrations of both. ${ }^{111}$ Results showed that in the presence of a low molecular weight surface active species e.g. Tween 80, the lipid nanoparticles initially formed were 

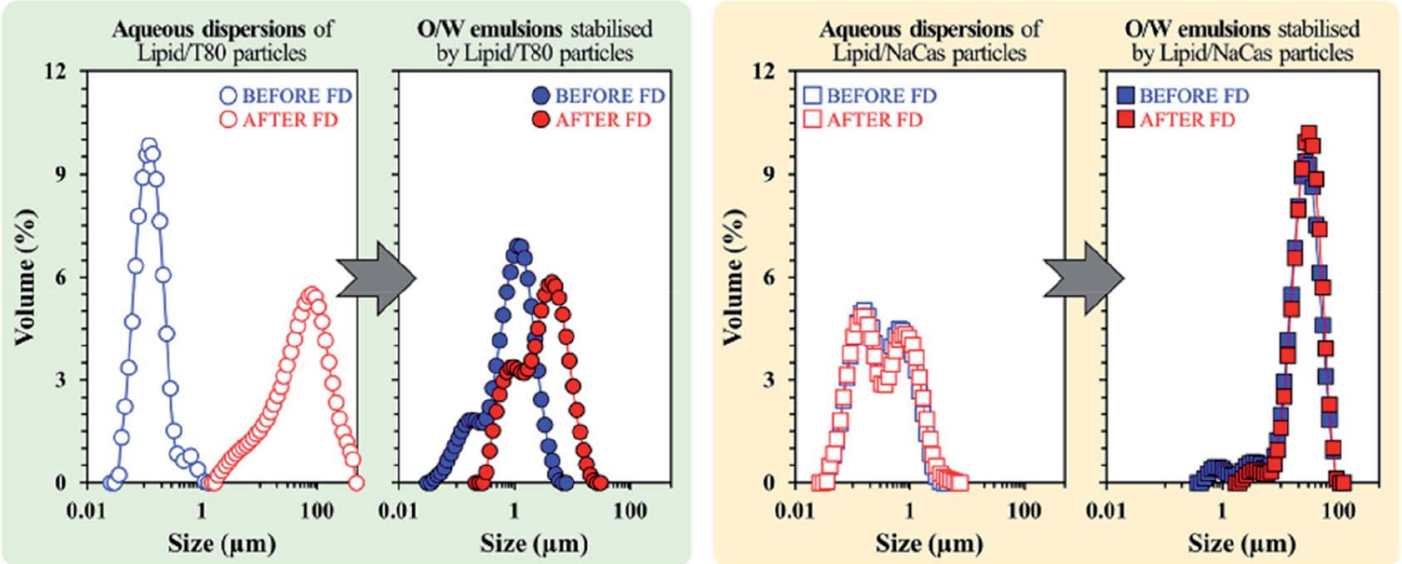

Fig. 11 Particle size distributions of SLN particles stabilised by Tween 80 (left) and sodium caseinate (right), before (blue) and after (red) lyophilisation. ${ }^{111}$ Reprinted from ref. 111, Copyright 2020, with permission from Elsevier.

uniform and submicron, in comparison to when a high molecular weight surface active species, sodium caseinate was present, giving larger but still uniform particles. Lipid particles formulated using sodium caseinate however, emerged as the superior choice, retaining the same particle size, microstructure and Pickering functionality with similar emulsion droplet sizes being formed before and after the freeze-drying and rehydration process (Fig. 11). The use of Tween 80 led to significantly increased particle sizes after lyophilisation which in turn led to larger emulsion droplets being stabilised (Fig. 11). It is promising that sodium caseinate, a naturally occurring milk protein, is the more effective stabiliser for this system as it is inherently more sustainable due to its bioderived nature in comparison to the surfactant Tween 80. Future research should look towards seeking out more bioderived SLN stabilisers like sodium caseinate as we move towards a more sustainable future.

\subsection{Oleofoams}

Oleofoams, best described as edible air-in-oil systems, ${ }^{112}$ can be made by the vigorous whipping of oleogels (Fig. 12), which in

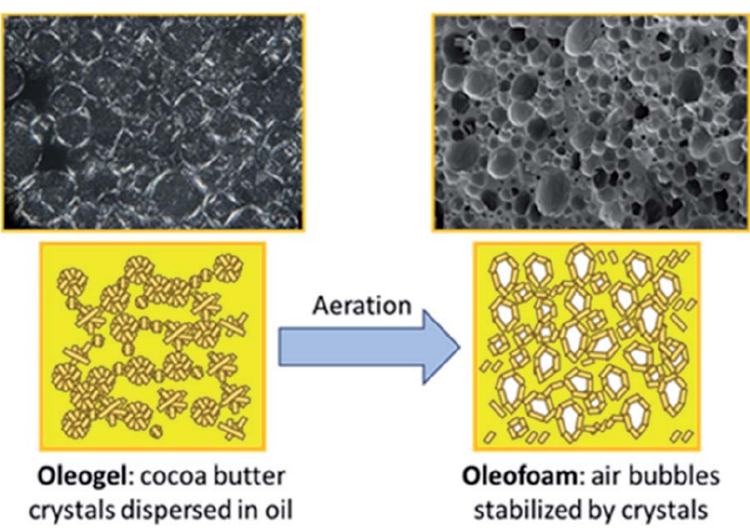

Fig. 12 Diagram showing the aeration of a cocoa butter oleogel to form crystal-stabilised air bubbles within the oil, known as oleofoams. ${ }^{112}$ Reprinted from ref. 112, Copyright 2021, with permission from American Chemical Society. turn are formed using gelators to create dispersions of lipid, fatty acid or wax crystals in a continuous oil phase. The fat crystals adsorb at the air-oleogel interface via a Pickering mechanism and prevent the coalescence of air bubbles. ${ }^{113}$ There has been some debate as to whether oleofoams can be classed as true Pickering emulsions as it is hypothesised that the trapped air bubbles may not only be stabilised by solid crystal particles but also by the slight bridging of crystals to form a strong network stabilisation. ${ }^{14,115}$ We discuss them in this review, however, as it is thought that the Pickering mechanism is critical to the stabilisation of the foam.

Oleofoams are much less common than their aqueous-based foam counterparts, with the low surface energy at the air-oil interface making them more difficult to prepare. ${ }^{116}$ However, they have received increased interest in recent years, particularly in the food industry as they can provide a reduced calorific content whilst still giving an aerated, smooth texture with similar rheological properties to their full-fat counterparts. ${ }^{112}$ Also, in contrast to aqueous foams, the lack of water present leads to less microbial spoilage with less requirement for preservatives. ${ }^{116}$ Research is restricted by the polymorphism and concentrations of fat crystals chosen to investigate since below a certain concentration, the crystals provide insufficient coverage to stabilise the air within the oil whereas above the optimal range, the oleogel becomes too difficult to aerate.

A recent study focused on how the shape, size, concentration and polymorphism of the fat crystals in the initial oleogel affected the microstructure, stability and rheological properties of the resulting oleofoam. ${ }^{112}$ The authors used cocoa butter (CB), high in saturated fats, as their high melting point fat, added to high-oleic sunflower oil at elevated temperatures before cooling. They found the oleofoam to be stabilised by CB nanoplatelets (up to $500 \mathrm{~nm}$ in size) in the $\beta(\mathrm{V})$ polymorph state with an air-volume fraction of up to $\varphi=0.60-0.66$. The diameters of the spherical fat crystal aggregates produced in the oleogel increased slightly upon longer cooling times, with the fastest cooled samples, approximately $-0.5{ }^{\circ} \mathrm{C}$ per minute, being around $40 \mu \mathrm{m}$ in size. The medium and slow cooled 

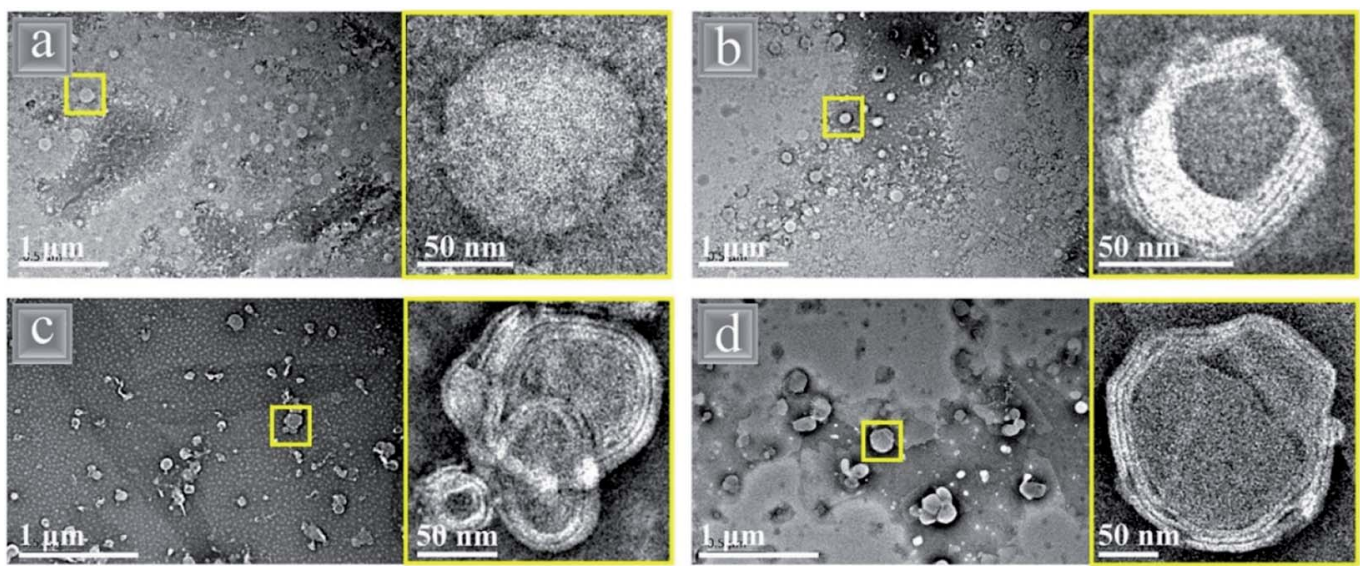

Fig. 13 TEM images of gliadin (G)-lecithin (L) core-shell nanoparticles with varying ratios of $G: L$ (a) $10: 0$, (b) $7: 3$, (c) $5: 5$ and (d) $3: 7.118$ Reprinted from ref. 118, Copyright 2019, with permission from American Chemical Society.

samples, at $\sim-0.2{ }^{\circ} \mathrm{C}$ and $-0.08{ }^{\circ} \mathrm{C}$ per minute, had larger aggregates of 50-60 $\mu \mathrm{m}$ and $100-150 \mu \mathrm{m}$, respectively. However, it was determined that the cooling rate of the CB crystals was not a defining factor in the overall production of the oleofoams as, during the aeration step, the temperature was raised $5-10{ }^{\circ} \mathrm{C}$ so some of the smaller CB crystals were dissolved, changing the size distribution and morphology range of the crystals but giving overall similar properties in the oleofoams from all of the precursor gels.

The overriding factor in the size and shape of the air bubbles was the $\mathrm{CB}$ content with $30 \% \mathrm{CB}$ w/w having a less efficient mean foam overrun and some unaerated oleogel crystals still present in the resulting oleofoam. The samples with lower concentrations of $15 \%$ and $22 \% \mathrm{w} / \mathrm{w}$ CB gave superior results with higher foam overrun. This reliance on crystal concentration was also shown by Du et al. ${ }^{115}$ as in that work, the increase of monoglyceride concentration led to tightly formed bubbles and stronger interfacial elasticity. This was thought to be due to a thicker crystal layer at the interface and an increased gelling within the continuous oil phase. ${ }^{\mathbf{1 1 5}}$

Hybrid oleofoams have also been formulated using mediumlong chain diacylglycerol (MLCD) and $\beta$-sitosterol (St) in varying ratios as the gelator components, interacting through hydrogen bonding. ${ }^{117}$ It was found that MLCD acted as the main Pickering stabiliser whilst St prevented the MLCD crystals from aggregating and synergistically improved the stabilisation and rigidity. The addition of diacylglycerol particles to fully hydrogenated palm oil (FHPO) was also found to form highly stable oil foams with high viscoelasticity through heterogeneous nucleation which gave a strong network system with less chance of oil drainage or air bubble coalescence. ${ }^{\mathbf{1 1 4}}$

\section{Hybrid particles in Pickering Emulsions}

\subsection{Protein-phospholipid hybrids}

Single component nanoparticles can have restricted particle properties and proteins, in particular, are sensitive to $\mathrm{pH}$, ionic strength and high temperatures, especially at the isoelectric point, which can lead to emulsion instability. However, proteins are arguably the best option for food grade nanoparticles due to their biocompatibility and vast range of surface active functional groups, so recent research has focused on reducing the sensitivity of protein nanoparticles whilst retaining their edibility by combining them with phospholipids to form composites.

Several recent studies have combined gliadin (G) protein with the phospholipid lecithin (L) using an anti- solvent coassembly to form core-shell like nanoparticles with a protein rich core and phospholipid rich multi-layer shell (Fig. 13). ${ }^{\mathbf{9 0 , 1 1 8 , 1 1 9}}$ The smallest nanoparticle diameter of $77.8 \mathrm{~nm}$ was formed with the smallest amount $(7: 3 \mathrm{G}: \mathrm{L})$ of phospholipid present, most likely due to small amounts of phospholipid having the ability to lower the surface tension and inhibit aggregation whereas larger amounts would cause bilayers of the phospholipids to form, creating larger diameters. It was found that the higher the phospholipid content of the nanoparticle, the more stable to changes in $\mathrm{pH}$, salt addition and heat the overall emulsion was and it also had an increased foamability. ${ }^{118}$ SDS-PAGE and FTIR confirmed that the composites were held together with hydrogen bonding, with no covalent bonds present and that the order of addition during the antisolvent co-assembly step could affect the interactions and structure of the nanoparticles. ${ }^{90}$ As well as their excellent potential as a foaming agent, the hybrid nanoparticles were used to encapsulate the hydrophobic nutraceuticals curcumin ${ }^{\mathbf{9 0}}$ and quercetin ${ }^{119}$ and reduce their degradation within the body, in comparison to pure gliadin nanoparticle emulsions.

\subsection{Protein-polysaccharide hybrids}

Protein surface modification with polysaccharides can also improve their wetting properties, ${ }^{\mathbf{1 2 0}}$ resistance to ionic strength, $\mathrm{pH}$ and temperature changes ${ }^{\mathbf{1 2 1}}$ and stability against creaming and flocculation. ${ }^{\mathbf{1 2 0}}$ By understanding, controlling and modulating the interactions that occur between proteins and polysaccharides, the resulting complexes can give superior 


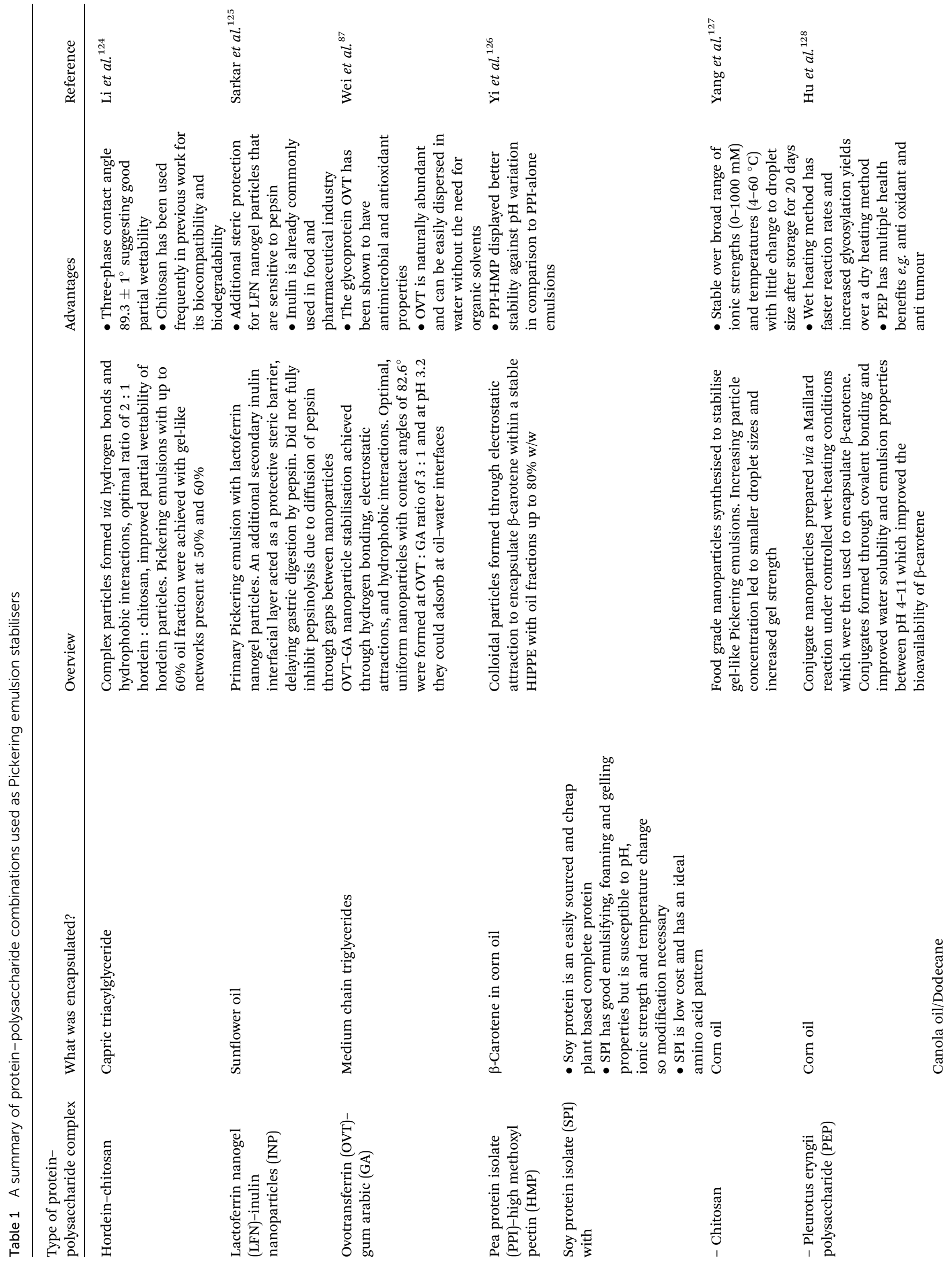




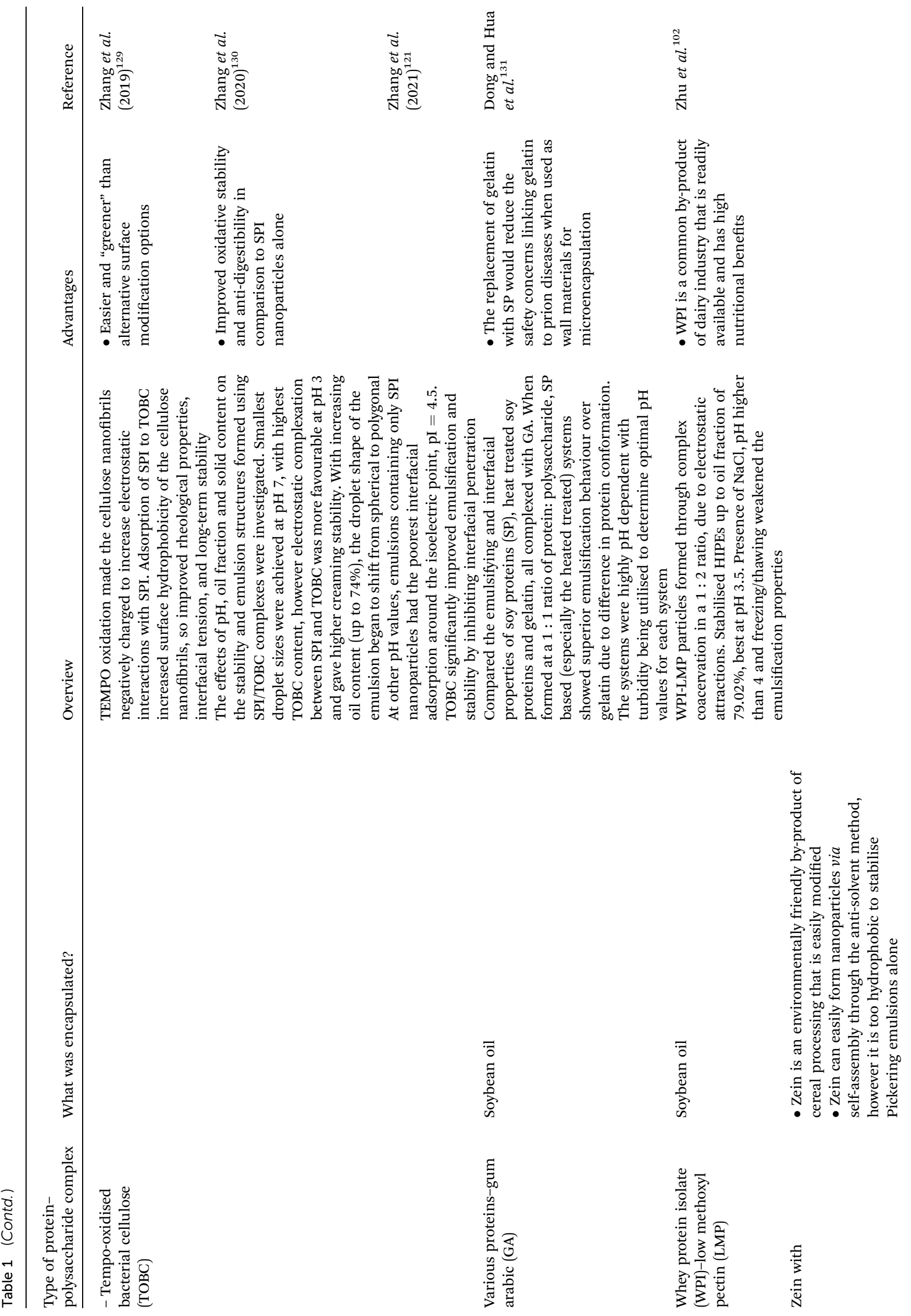




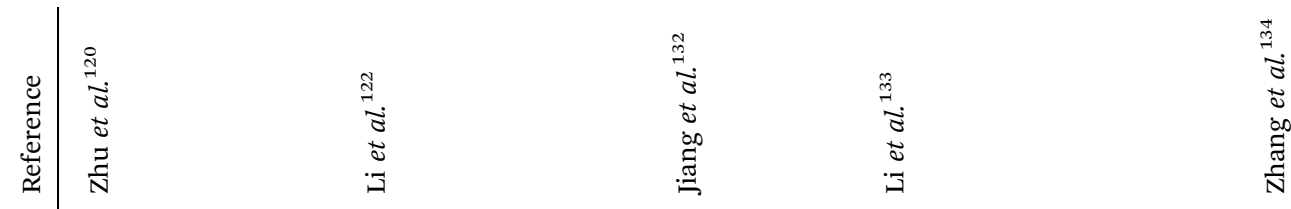

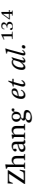
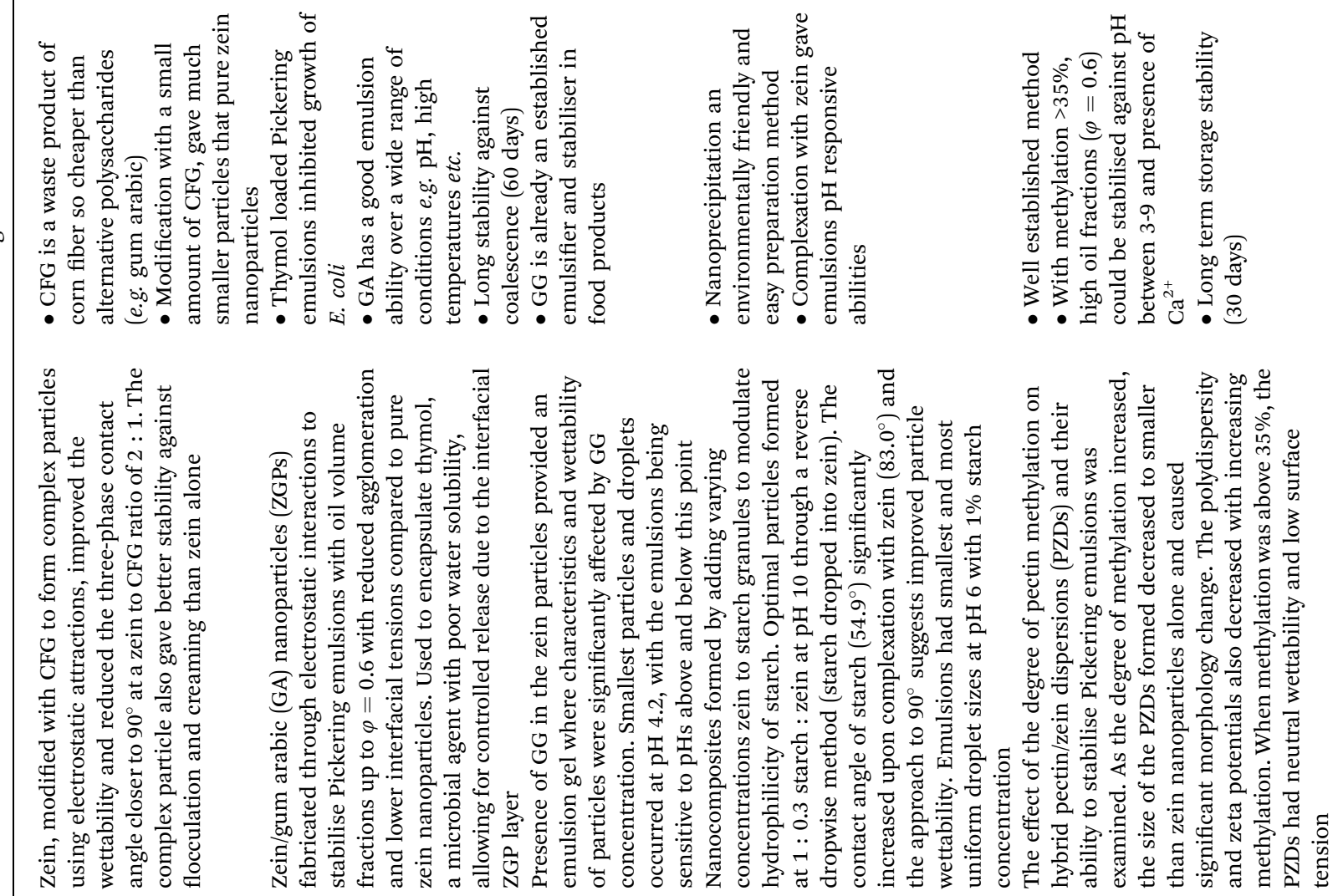


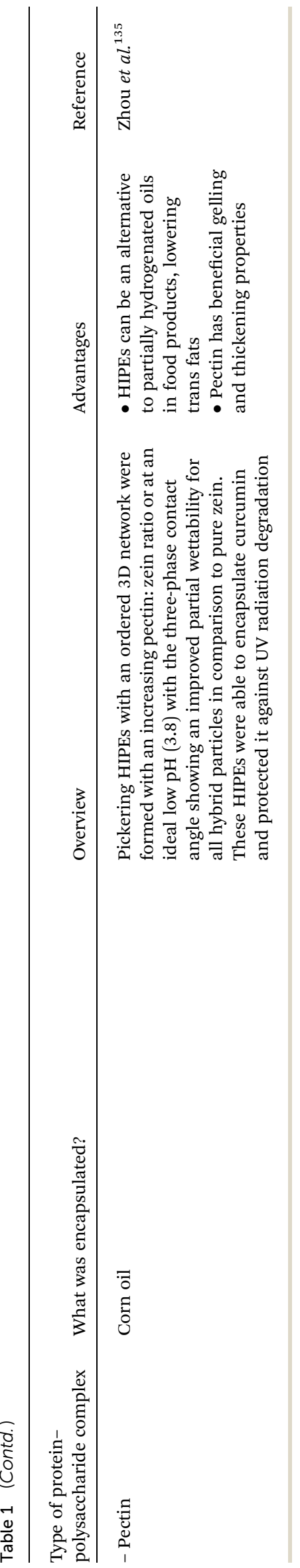

functional and emulsifying properties. As proteins can change conformation and zeta potential due to $\mathrm{pH}$, the strength of interaction between the positively charged protein, below the pI (isoelectric point), and the (usually) negatively charged polysaccharide can vary significantly, influencing emulsion properties. A commonly investigated Pickering particle, zein, is a prolamin based protein, rich in hydrophobic amino acid residues, that is a by-product from the cereal processing industry. It can be used without modification as Pickering nanoparticles but due to its highly hydrophobic nature and lack of wettability, especially at pH's close to the isoelectric point, it tends to aggregate easily. Their high hydrophobicity is excellent at encapsulating hydrophobic biomolecules, however, so a common solution to improve the emulsion stabilities is to cross-link the protein with natural biopolymers such as gum arabic, ${ }^{122}$ chitosan ${ }^{79}$ and corn fibre gum. ${ }^{120}$ These biopolymers have been shown to reduce the contact angle and hydrophobicity of the zein particles, improving the emulsifying properties and stability of the Pickering emulsion.

Along with the above mentioned non-covalent interactions to form particle complexes, proteins can also form covalent conjugates through the Maillard reaction, or via chemical or enzymatic cross-linking with polysaccharides. A recent perspective paper highlighted how the design of protein-polysaccharide delivery vehicles for bioactive ingredients can be tailored depending on the bonding mechanism of the complex to fit different delivery needs. ${ }^{123}$ It also discussed the challenges that must be overcome in this area including low loading capabilities and the need for targeted and controlled release. ${ }^{123}$ As there is such a wide variety of protein-polysaccharide combinations available, investigation into the effects of different types is ongoing and a selection of recent studies have been summarised in Table 1 to give a flavour of this area of work.

\section{Summary}

Pickering emulsions stabilised by various biodegradable solid particles and macromolecules have proven to be an excellent alternative to synthetic surfactant-based emulsions. The stability of Pickering emulsions investigated so far depends largely on the inherent properties of the stabilising material. Therefore, it is apparent that some challenges still remain, the most prominent of which is the poor stabilisation ability of unmodified bio-derived particles. Additional modification/ functionalisation is then required, which can involve corrosive or toxic synthetic chemicals to impart desirable wetting properties for stable emulsion formation. However, the most recent work demonstrates that by combining natural materials, the ability to design bio-based particles with lower environmental impact is being dramatically improved. In addition, relatively high energy methods such as homogenisation and ultrasonication are often required to effectively absorb these solid particles at the oil-water interface. Therefore, future research warrants still more focus on probing lower energy routes to effective emulsification as well as on sustainable and greener approaches for functionalising these solid stabilisers, building 
on the active research in composite particles, to allow production of sustainable Pickering emulsions for safer consumer goods, biomedical formulations and industrial applications.

\section{Conflicts of interest}

The authors declare no conflict of interest.

\section{References}

1 M. A. Hussein, A. A. Mohammed and M. A. Atiya, Environ. Sci. Pollut. Res., 2019, 26, 36184-36204.

2 D. Gonzalez Ortiz, C. Pochat-Bohatier, J. Cambedouzou, M. Bechelany and P. Miele, Engineering, 2020, 6, 468-482.

3 L. Chen, F. Ao, X. Ge and W. Shen, Molecules, 2020, 25, 3202. 4 C. Albert, M. Beladjine, N. Tsapis, E. Fattal, F. Agnely and N. Huang, J. Controlled Release, 2019, 309, 302-332.

5 B. S. Murray, Curr. Opin. Food Sci., 2019, 27, 57-63.

6 E. Dickinson, Curr. Opin. Food Sci., 2020, 33, 52-60.

7 W. Ramsden and F. Gotch, Proc. R. Soc. London, 1903, 72, 156-164.

8 S. U. Pickering, J. Chem. Soc., Trans., 1907, 91, 2001-2021.

9 V. Calabrese, J. C. Courtenay, K. J. Edler and J. L. Scott, Curr. Opin. Green Sustain. Chem., 2018, 12, 83-90.

10 W. J. Han, H. J. Choi and Y. Seo, Smart Mater. Struct., 2020, 29, 085022.

11 F. Lou, L. Ye, M. Kong, Q. Yang, G. Li and Y. Huang, RSC Adv., 2016, 6, 24195-24202.

12 M. Sun, W. Yin, J. Chen, W. Wang, T. Guo and T. Meng, Green Chem., 2021, 23, 740-744.

13 L.-H. Xue, C.-Y. Xie, S.-X. Meng, R.-X. Bai, X. Yang, Y. Wang, S. Wang, B. P. Binks, T. Guo and T. Meng, ACS Macro Lett., 2017, 6, 679-683.

14 E. Atefi, J. A. Mann and H. Tavana, Langmuir, 2014, 30, 9691-9699.

15 E. Ben Ayed, R. Cochereau, C. Dechancé, I. Capron, T. Nicolai and L. Benyahia, Langmuir, 2018, 34, 6887-6893.

16 Y. Yang, Z. Fang, X. Chen, W. Zhang, Y. Xie, Y. Chen, Z. Liu and W. Yuan, Front. Pharmacol., 2017, 8, 287.

17 M. Xiao, A. Xu, T. Zhang and L. Hong, Front. Chem., 2018, 6, 225.

18 H. Jiang, Y. Sheng and T. Ngai, Curr. Opin. Colloid Interface Sci., 2020, 49, 1-15.

19 D. Trache, M. H. Hussin, M. K. M. Haafiz and V. K. Thakur, Nanoscale, 2017, 9, 1763-1786.

20 M. Shahrousvand, F. A. Tabar, E. Shahrousvand, A. Babaei, M. M. Hasani-Sadrabadi, G. M. M. Sadeghi, H. Jafari and A. Salimi, Carbohydr. Polym., 2017, 175, 293-302.

21 A. Dufresne, Mater. Today, 2013, 16, 220-227.

22 H. Zhang, Y. Chen, S. Wang, L. Ma, Y. Yu, H. Dai and Y. Zhang, Carbohydr. Polym., 2020, 238, 116180.

23 J. Han, C. Zhou, Y. Wu, F. Liu and Q. Wu, Biomacromolecules, 2013, 14, 1529-1540.

24 A. Pirozzi, R. Capuano, R. Avolio, G. Gentile, G. Ferrari and F. Donsì, Foods, 2021, 10, 1886.

25 A. A. D. Meirelles, A. L. R. Costa and R. L. Cunha, Int. J. Biol. Macromol., 2020, 158, 75-84.
26 L. Bai, S. Lv, W. Xiang, S. Huan, D. J. McClements and O. J. Rojas, Food Hydrocolloids, 2019, 96, 699-708.

27 H. Dai, J. Wu, H. Zhang, Y. Chen, L. Ma, H. Huang, Y. Huang and Y. Zhang, Trends Food Sci. Technol., 2020, 102, 16-29.

28 I. Kalashnikova, H. Bizot, B. Cathala and I. Capron, Biomacromolecules, 2012, 13, 267-275.

29 K. M. Z. Hossain, V. Calabrese, M. A. da Silva, J. Schmitt, S. J. Bryant, M. T. Islam, R. M. Felfel, J. L. Scott and K. J. Edler, Macromol. Mater. Eng., 2021, 306, 2000462.

30 K. M. Z. Hossain, V. Calabrese, M. A. da Silva, S. J. Bryant, J. Schmitt, J. L. Scott and K. J. Edler, Carbohydr. Polym., 2020, 233, 115816.

31 I. Anton-Sales, S. Roig-Sanchez, M. J. Sánchez-Guisado, A. Laromaine and A. Roig, ACS Biomater. Sci. Eng., 2020, 6, 4893-4902.

32 S. Varanasi, L. Henzel, L. Mendoza, R. Prathapan, W. Batchelor, R. Tabor and G. Garnier, Front. Chem., 2018, 6, 409.

33 Z. Hu, S. Ballinger, R. Pelton and E. D. Cranston, J. Colloid Interface Sci., 2015, 439, 139-148.

34 X. Li, J. Li, J. Gong, Y. Kuang, L. Mo and T. Song, Carbohydr. Polym., 2018, 183, 303-310.

35 Q.-H. Chen, J. Zheng, Y.-T. Xu, S.-W. Yin, F. Liu and C.-H. Tang, Food Hydrocolloids, 2018, 75, 125-130.

36 H. Du Le, S. M. Loveday, H. Singh and A. Sarkar, Food Hydrocolloids, 2020, 99, 105344.

37 S. Ye, H.-Y. Yu, D. Wang, J. Zhu and J. Gu, Cellulose, 2018, 25, 5139-5155.

38 C. Tang, S. Spinney, Z. Shi, J. Tang, B. Peng, J. Luo and K. C. Tam, Langmuir, 2018, 34, 12897-12905.

39 J. Wang, F. Ren, J. Yu, S. Wang, L. Copeland and S. Wang, ACS Sustainable Chem. Eng., 2020, 8, 16503-16514.

40 B. Mahadevan, B. A. Thorsrud, G. P. Brorby and H. E. Ferguson, Food Chem. Toxicol., 2014, 72, 83-89.

41 C. Tang, Y. Chen, J. Luo, M. Y. Low, Z. Shi, J. Tang, Z. Zhang, B. Peng and K. C. Tam, Cellulose, 2019, 26, 7753-7767.

42 L. Bai, S. Huan, W. Xiang and O. J. Rojas, Green Chem., 2018, 20, 1571-1582.

43 M. Nordenström, A. Fall, G. Nyström and L. Wågberg, Langmuir, 2017, 33, 9772-9780.

44 R. J. Moon, A. Martini, J. Nairn, J. Simonsen and J. Youngblood, Chem. Soc. Rev., 2011, 40, 3941-3994.

45 Y. Habibi, L. A. Lucia and O. J. Rojas, Chem. Rev., 2010, 110, 3479-3500.

46 M. T. Islam, M. M. Alam, A. Patrucco, A. Montarsolo and M. Zoccola, AATCC J. Res., 2014, 1, 17-23.

47 C. Moser, M. E. Lindström and G. Henriksson, BioResources, 2015, 10(2), 2015.

48 E. Kaffashsaie, H. Yousefi, T. Nishino, T. Matsumoto, M. Mashkour, M. Madhoushi and H. Kawaguchi, Carbohydr. Polym., 2021, 262, 117938.

49 A. Isogai and Y. Zhou, Curr. Opin. Solid State Mater. Sci., 2019, 23, 101-106.

50 S. J. Bryant, M. A. da Silva, K. M. Z. Hossain, V. Calabrese, J. L. Scott and K. J. Edler, RSC Adv., 2020, 10, 37023-37027. 
51 J. C. Courtenay, Y. Jin, J. Schmitt, K. M. Z. Hossain, N. Mahmoudi, K. J. Edler and J. L. Scott, Langmuir, 2021, 37, 6864-6873.

52 S. Ummartyotin and H. Manuspiya, Renewable Sustainable Energy Rev., 2015, 41, 402-412.

53 A. Isogai, T. Saito and H. Fukuzumi, Nanoscale, 2011, 3, 7185.

54 X. Li, J. Li, Y. Kuang, S. Guo, L. Mo and Y. Ni, Cellulose, 2020, 27, 839-851.

55 Y. Goi, S. Fujisawa, T. Saito, K. Yamane, K. Kuroda and A. Isogai, Langmuir, 2019, 35, 10920-10926.

56 K.-Y. Lee, T. Tammelin, K. Schulfter, H. Kiiskinen, J. Samela and A. Bismarck, ACS Appl. Mater. Interfaces, 2012, 4, 40784086.

57 H. Yan, X. Chen, M. Feng, Z. Shi, W. Zhang, Y. Wang, C. Ke and Q. Lin, Colloids Surf., B, 2019, 177, 112-120.

58 X. Zhai, D. Lin, D. Liu and X. Yang, Food Res. Int., 2018, 103, 12-20.

59 J. L. Sanchez-Salvador, A. Balea, M. C. Monte, A. Blanco and C. Negro, Appl. Sci., 2019, 9, 359.

60 E. Bertoft, Agronomy, 2017, 7, 56.

61 C. Wang, X. Fu, C.-H. Tang, Q. Huang and B. Zhang, Food Chem., 2017, 227, 298-304.

62 L. X. Xian, N. Y. Shariffa, M. L. Azwan and U. Uthumporn, Food Res., 2020, 4, 753-763.

63 A. Marefati and M. Rayner, J. Sci. Food Agric., 2020, 100, 2807-2811.

64 H. Saari, M. Wahlgren, M. Rayner, M. Sjöö and M. Matos, PLoS One, 2019, 14, e0210690.

65 W. Zhang, B. Cheng, J. Li, Z. Shu, P. Wang and X. Zeng, Polymers, 2021, 13, 1325.

66 E. J. Leal-Castañeda, Y. García-Tejeda, H. HernándezSánchez, L. Alamilla-Beltrán, D. I. Téllez-Medina, G. Calderón-Domínguez, H. S. García and G. F. GutiérrezLópez, Food Hydrocolloids, 2018, 80, 177-185.

67 H. Saari, K. Heravifar, M. Rayner, M. Wahlgren and M. Sjöö, Cereal Chem., 2016, 93, 116-124.

68 Q. Sun, in Starch in Food, ed. M. Sjöö and L. Nilsson, Woodhead Publishing, 2018, 2nd edn, pp. 691-745, DOI: 10.1016/B978-0-08-100868-3.00018-4.

69 H. Saari, C. Fuentes, M. Sjöö, M. Rayner and M. Wahlgren, Carbohydr. Polym., 2017, 157, 558-566.

70 X. Lu, J. Xiao and Q. Huang, Food Res. Int., 2018, 105, 140149.

71 M. H. Asfour, H. Elmotasem, D. M. Mostafa and A. A. A. Salama, Int. J. Pharm., 2017, 534, 325-338.

72 H. Tian, Z. Lu, H. Yu, C. Chen and J. Hu, Food Funct., 2019, 10, 2595-2604.

73 X.-Y. Wang and M.-C. Heuzey, RSC Adv., 2016, 6, 8977689784.

74 C. Yan, D. J. McClements, Y. Zhu, L. Zou, W. Zhou and W. Liu, J. Agric. Food Chem., 2019, 67, 10937-10946.

75 A. Sharkawy, M. F. Barreiro and A. E. Rodrigues, Carbohydr. Polym., 2020, 250, 116885.

76 A. Sharkawy, M. F. Barreiro and A. E. Rodrigues, Carbohydr. Polym., 2019, 224, 115190.
77 S. Chen and L.-M. Zhang, Colloids Surf., A, 2019, 579, 123662.

78 X. Yang, Y. Wang, R. Bai, H. Ma, W. Wang, H. Sun, Y. Dong, F. Qu, Q. Tang, T. Guo, B. P. Binks and T. Meng, Green Chem., 2019, 21, 2229-2233.

79 B. R. Shah, W. Xu and J. Mráz, J. Sci. Food Agric., 2021, 101, 5419-5428.

80 X. Yan, C. Ma, F. Cui, D. J. McClements, X. Liu and F. Liu, Trends Food Sci. Technol., 2020, 103, 293-303.

81 T. Zhang, J. Xu, J. Chen, Z. Wang, X. Wang and J. Zhong, Trends Food Sci. Technol., 2021, 113, 26-41.

82 Q. Zhao, F. Zaaboul, Y. Liu and J. Li, Compr. Rev. Food Sci. Food Saf., 2020, 19, 1934-1968.

83 S. Zhang, M. Holmes, R. Ettelaie and A. Sarkar, Food Hydrocolloids, 2020, 102, 105583.

84 J.-S. Wang, A.-B. Wang, X.-P. Zang, L. Tan, B.-Y. Xu, H.-H. Chen, Z.-Q. Jin and W.-H. Ma, Food Chem., 2019, 288, 146-153.

85 F. Ning, Z. Ge, L. Qiu, X. Wang, L. Luo, H. Xiong and Q. Huang, Food Hydrocolloids, 2020, 99, 105308.

86 B. Jiao, A. Shi, Q. Wang and B. P. Binks, Angew. Chem., Int. Ed., 2018, 57, 9274-9278.

87 Z. Wei, J. Zhu, Y. Cheng and Q. Huang, Food Res. Int., 2019, 125, 108602.

88 J. Yan, X. Liang, C. Ma, D. J. McClements, X. Liu and F. Liu, Food Hydrocolloids, 2021, 113, 106473.

89 R. Meng, Z. Wu, Q.-T. Xie, B. Zhang, X.-L. Li, W.-J. Liu, H. Tao and P.-J. Li, Food Hydrocolloids, 2020, 108, 106020.

90 S. Yang, L. Dai, C. Sun and Y. Gao, Food Hydrocolloids, 2018, 85, 185-194.

91 G. Liu, Q. Wang, Z. Hu, J. Cai and X. Qin, J. Agric. Food Chem., 2019, 67, 5212-5220.

92 Q. Tang, X. Xie, C. Li, B. Zhen, X. Cai, G. Zhang, C. Zhou and L. Wang, Colloids Surf., B, 2019, 183, 110414.

93 S. Guo and Y. Zhang, Colloids Surf., A, 2019, 562, 119-126.

94 V. O. Ikem, A. Menner and A. Bismarck, Langmuir, 2010, 26, 8836-8841.

95 Q. Zhao, Q. Gu, X. Hong, Y. Liu and J. Li, LWT, 2021, 145, 111340.

96 Y. Guo, C. Wu, M. Du, S. Lin, X. Xu and P. Yu, LWT, 2021, 139, 110538.

97 Q. Zhao, L. Wang, X. Hong, Y. Liu and J. Li, Food Hydrocolloids, 2021, 113, 106412.

98 L. Wang, J. Wang and A. Wang, Foods, 2021, 10, 599.

99 A. Araiza-Calahorra and A. Sarkar, Food Struct., 2019, 21, 100113.

100 Z. Wang, N. Zhang, C. Chen, R. He and X. Ju, J. Agric. Food Chem., 2020, 68, 3607-3614.

101 J. Wu, M. Shi, W. Li, L. Zhao, Z. Wang, X. Yan, W. Norde and Y. Li, Colloids Surf., B, 2015, 127, 96-104.

102 C.-P. Zhu, H.-H. Zhang, G.-Q. Huang and J.-X. Xiao, J. Dispersion Sci. Technol., 2020, 1-12, DOI: 10.1080/ 01932691.2020.1724801.

103 S. Zamani, N. Malchione, M. J. Selig and A. Abbaspourrad, Food Funct., 2018, 9, 982-990.

104 P. Lv, D. Wang, L. Dai, X. Wu, Y. Gao and F. Yuan, Food Res. Int., 2020, 132, 109032. 
105 J. T. do Prado Silva, J. V. Benetti, T. T. Alexandrino, O. B. Assis, J. de Ruiter, K. Schroën and V. R. Nicoletti, Foods, 2021, 10, 1296.

106 S. M. Dieng, N. Anton, P. Bouriat, O. Thioune, P. M. Sy, N. Massaddeq, S. Enharrar, M. Diarra and T. Vandamme, Soft Matter, 2019, 15, 8164-8174.

107 G. I. Sakellari, I. Zafeiri, A. Pawlik, D. Kurukji, P. Taylor, I. T. Norton and F. Spyropoulos, J. Colloid Interface Sci., 2021, 587, 644-649.

108 H. Lim, M. Jo, C. Ban and Y. J. Choi, Food Chem., 2020, 306, 125619.

109 J. Milsmann, K. Oehlke, K. Schrader, R. Greiner and A. Steffen-Heins, Colloids Surf., A, 2018, 558, 615-622.

110 I. Zafeiri, J. E. Norton, P. Smith, I. T. Norton and F. Spyropoulos, J. Colloid Interface Sci., 2017, 500, 228-240.

111 I. Zafeiri, P. Smith, I. T. Norton and F. Spyropoulos, Colloids Surf., A, 2020, 599, 124916.

112 L. Metilli, A. Lazidis, M. Francis, S. Marty-Terrade, J. Ray and E. Simone, Cryst. Growth Des., 2021, 21, 1562-1575.

113 D. Z. Gunes, M. Murith, J. Godefroid, C. Pelloux, H. Deyber, O. Schafer and O. Breton, Langmuir, 2017, 33, 1563-1575.

114 M. Lei, N. Zhang, W. J. Lee, C. P. Tan, O. M. Lai, Y. Wang and C. Qiu, Food Chem., 2020, 312, 126047.

115 L. Du, Q. Jiang, S. Li, Q. Zhou, Y. Tan and Z. Meng, Food Hydrocolloids, 2021, 112, 106245.

116 A.-L. Fameau and A. Saint-Jalmes, Front. Sustain. Food Syst., 2020, 4, 110.

117 C. Qiu, M. Lei, W. J. Lee, N. Zhang and Y. Wang, Food Chem., 2021, 350, 129275.

118 X. Chen, Y. Chen, L. Zou, X. Zhang, Y. Dong, J. Tang, D. J. McClements and W. Liu, J. Agric. Food Chem., 2019, 67, 6574-6584.

119 X. Chen, Y. Chen, Y. Huang, L. Zou, C. Liu, D. J. McClements and W. Liu, ACS Appl. Nano Mater., 2019, 2, 6462-6472.
120 Q. Zhu, H. Lu, J. Zhu, M. Zhang and L. Yin, Food Hydrocolloids, 2019, 91, 204-213.

121 X. Zhang, Y. Lei, X. Luo, Y. Wang, Y. Li, B. Li and S. Liu, Food Hydrocolloids, 2021, 115, 106609.

122 J. Li, X. Xu, Z. Chen, T. Wang, Z. Lu, W. Hu and L. Wang, Carbohydr. Polym., 2018, 200, 416-426.

123 Z. Wei and Q. Huang, J. Agric. Food Chem., 2019, 67, 13441352.

124 F. Li, X. Li, K. Huang, Y. Luo and X. Mei, J. Food Eng., 2021, 292, 110275.

125 A. Sarkar, V. Ademuyiwa, S. Stubley, N. H. Esa, F. M. Goycoolea, X. Qin, F. Gonzalez and C. Olvera, Food Hydrocolloids, 2018, 84, 282-291.

126 J. Yi, C. Gan, Z. Wen, Y. Fan and X. Wu, Food Hydrocolloids, 2021, 113, 106497.

127 H. Yang, Z. Su, X. Meng, X. Zhang, J. F. Kennedy and B. Liu, Carbohydr. Polym., 2020, 247, 116712.

128 Q. Hu, Y. Wu, L. Zhong, N. Ma, L. Zhao, G. Ma, N. Cheng, P. A. Nakata and J. Xu, Food Hydrocolloids, 2021, 112, 106340.

129 X. Zhang, Y. Liu, Y. Wang, X. Luo, Y. Li, B. Li, J. Wang and S. Liu, Food Hydrocolloids, 2019, 97, 105180.

130 X. Zhang, X. Luo, Y. Wang, Y. Li, B. Li and S. Liu, Food Hydrocolloids, 2020, 108, 106025.

131 D. Dong and Y. Hua, Food Hydrocolloids, 2018, 74, 289-295.

132 Y. Jiang, C. Zhang, J. Yuan, Y. Wu, F. Li, G. I. N. Waterhouse, D. Li and Q. Huang, Food Chem., 2021, 349, 129112.

133 S. Li, L. Huang, B. Zhang, C. Chen, X. Fu and Q. Huang, Food Hydrocolloids, 2021, 112, 106341.

134 W. Zhang, X. Gu, X. Liu and Z. Wang, Carbohydr. Polym., 2021, 256, 117515.

135 F.-Z. Zhou, X.-N. Huang, Z.-l. Wu, S.-W. Yin, J.-h. Zhu, C.-H. Tang and X.-Q. Yang, J. Agric. Food Chem., 2018, 66, 11113-11123. 